\title{
A holistic model for measuring continuous innovation capability of manufacturing industry: a case study
}

Holistic model for measuring CIC

\author{
Benny Lianto \\ Department of Industrial Engineering, University of Surabaya, \\ Surabaya, Indonesia and \\ Department of Industrial Engineering, Universitas Indonesia, Depok, Indonesia \\ Muhammad Dachyar \\ Department of Industrial Engineering, Universitas Indonesia, Depok, Indonesia, and \\ Tresna Priyana Soemardi \\ Department of Mechanical Engineering, Universitas Indonesia, Depok, Indonesia
}

Received 2 February 2021 Revised 7 May 2021 29 June 2021 6 July 2021 Accepted 7 July 2021

\begin{abstract}
Purpose - The purpose of this paper is to develop a comprehensive continuous innovation capability (CIC) measurement model in manufacturing sectors.

Design/methodology/approach - The development of this CIC model was conducted through three stages of research, i.e. identification of manufacturing continuous innovation measures (MCIMs), development of measurement model, followed by model evaluation and validation. MCIMs were identified using systematic literature review and focus group discussion. Selection process for MCIMs employed the fuzzy Delphi method. To develop measurement model, contextual relationships between MCIMs were assessed using total interpretive structural modeling, followed by measurements of MCIMs weight with the analytical network process method. Then, assessment indicators for each MCIM and criteria were determined as well as mathematical model to measure CIC scores. Model evaluation and validation were performed in two case studies: in an automotive company and an electronics company.

Findings - This research produced 50 criteria and 103 assessment indicators, as well as mathematical model to measure CIC scores. The validation process showed that currently developed model was deemed valid. Practical implications - The results of this research are expected to provide a practical input for manufacturing company managers in managing their innovation activities systematically and comprehensively.

Originality/value - The CIC model is a new comprehensive measurement model; it integrates three fundamental elements of CI capability measurement, considering all important dimensions in a company and also able to explain contextual relationships between measured factors.
\end{abstract}

Keywords Holistic model, Continuous innovation, Performance measurement, Manufacturing

Paper type Research paper

\section{Introduction}

To face the great challenges of Industry 4.0 and rapidly changing industry environment, the manufacturing industry needs continuous innovation capability (Stålberg, 2018). Javahernia and Sunmola (2017) stated that continuous innovation capability (CIC), that is the ability to continuously innovate, is needed by the manufacturing industry today, so the industry can have high competitiveness and continue to survive; by continuously producing new products, new processes, new service systems and new business models so their products and

The authors would like to thank University of Surabaya (UBAYA) and Universitas Indonesia (UI) for permits and support this research funding.

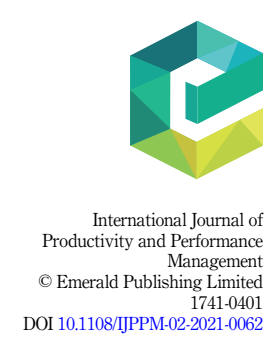


services are always relevant to market's changing needs. Companies can manage their innovation performance optimally, effectively and sustainably if they continue to measure and monitor their capabilities in innovating (Phan, 2013). It means that measuring CIC is very crucial because by doing so, a company can ascertain whether the development of innovation activities is carried out continuously and leads to the formation of ability to continuously innovate in all parts of the company (Edison et al., 2013). In such a situation, the development and selection of valid and appropriate measurement methods to assess a company's ability to continuously innovate becomes an urgent need (Steiber and Alänge, 2013).

Various models to measure the innovation capability in the manufacturing industry have been developed with various approaches by previous researchers (Altuntas et al., 2016; Boly et al., 2014; Carayannis and Provance, 2008; Lawson and Samson, 2001; Schroeder et al., 1989; Sun et al., 2012; Yamin et al., 1999; Ab Rahman et al., 2015; Nisula and Kianto, 2013; Phan, 2013; Steiber and Alänge, 2013). However, these measurement models have limitations. One of them is how the models "measure parts but not the whole" (Richtnér et al., 2017). In reality, to face future challenges and ensure sustainable innovation performance, a holistic innovation capability measurement model is needed (Dewangan and Godse, 2014; Rabelo and Bernus, 2015). This study attempts to improve the measurement model of CIC in the manufacturing industry based on three limitations as follows: First, they do not measure the capabilities of all important dimensions determining a company's innovation capability comprehensively. Second, the measurement models have yet to fully apply the basic principles of measuring innovation capability, and third, previous models are not able to explain relationship between factors measured.

The purpose of this paper is to fill in the gap in developing a more comprehensive and holistic measurement model for $\mathrm{CIC}$ in the manufacturing industry. The term holistic refers to these points: (1) the measurement model will fully implement the three basic principles of innovation capability measurement, i.e. innovation potential, innovation process and innovation results in an integrated and balanced manner; (2) the measurement model will measure innovation capability across all important dimensions in a company based on the six management principles of continuous innovation (CI) and (3) the measurement model will explain relationship pattern between factors measured.

The results of this research are expected to offer practical input for manufacturing industry managers to improve $\mathrm{CIC}$, preparing the company to enter dynamic environment and business competition in the era of Industry 4.0.

\section{Literature review}

This section is aimed at discussing relevant concepts and previous research related to this study.

\subsection{Continuous innovation}

CI has become one of the hot topics in the field of innovation management. CI can be defined from various points of view. Boer et al. (2001) stated that CI is a process of continuous interaction between operating activities, gradual improvement and radical innovation, resulting from an effective combination of operational and strategic aspects. From this point of view, CI is a process and innovation activity that is carried out continuously, constantly, regularly, repeatedly, in a structured manner, and over a long period of time and that brings benefits to the company. Steiber and Alänge (2013) stated that CI is the ability to continuously innovate and renew an organization to develop new products and business models. From another perspective, CI can be defined as the ability of a company to continuously learn and update itself so that it can continue to produce new products, processes, organizations and 
business models. Xie et al. (2011) said that CI is a continuous learning process that renews itself to create self-sustaining and reinforcing processes. CI can also be defined as the ability of a company to act quickly and adapt to meet current consumer needs and anticipate future consumer demands and needs. Teece and Pisano (1994) stated that CI is the capacity for timely responsiveness and rapid product innovation, coupled with the management capability to effectively coordinate and redeploy internal and external competencies. Comprehensively, $\mathrm{CI}$ can be defined as an innovation process and activity which is carried out continuously, routinely, repeatedly, over a long period of time and brings benefits to the company so as to form a continuous learning culture to continually renew themselves and act quickly to adjust to the needs of current consumers and the ability to anticipate future consumer demands and needs (Lianto et al., 2018).

\subsection{Latest challenges in measuring innovation capability}

The business environment and manufacturing industry are very dynamic. This characteristic requires changes in measuring innovation capabilities, so companies can adapt swiftly. Several researchers stated that in order to react to future challenges and ensure sustainable innovation performance, a more holistic innovation capability measurement model is needed; and it is important to perceive innovation from a more systemic and holistic paradigm (Dewangan and Godse, 2014; Rabelo and Bernus, 2015). Meanwhile, Chutivongse and Gerdsri (2018) postulated that in a rapidly changing industrial environment, innovation management in a company can be performed effectively if innovation activities are developed sustainably and continuously. Saunila and Ukko (2012) suggested three main elements that are essential in measuring innovation capability, i.e. innovation potential, innovation process and innovation result. Exploration and optimal use of innovation potential is important to determine the success of innovation activities. If the activities in the innovation process run well, it is expected that the innovation results will also be good. By extension, good innovation results will have an impact on the company's innovation and performance, thus assisting the company to continuously improve its innovation potential. If this integrated cycle can be maintained in the long run, it can foster the ability to continuously innovate. The existing measurements of innovation capabilities are more likely to use measurement indicators that are more oriented toward innovation results (outputs, outcomes), such as the number of patents (Belammy et al., 2014) and the number of sales originating from new products (Delgado-Varde et al., 2011). Other measurement models use indicators focusing on the innovation process, such as the number of innovation projects (Richtnér et al., 2017) and several innovation capability measurement models use indicators that are more related to innovation potential (inputs), such as R\&D intensities (Hong et al., 2015) and R\&D expenditure (Rasiah et al., 2016).

Another challenge is that based on one of the basic principles of the holistic Innovation Performance Measurement (IPM) scheme, the measurement of innovation performance must be multidimensional (Dewangan and Godse, 2014). Steiber (2014) proposed the concept of six management principles of CI, i.e. dynamic capabilities, a continuously changing organization, a people-centric approach, an ambidextrous organization, an open organization that networks with its surroundings and a systems approach. Based on mapping results of various factors and dimensions used by previous innovation capability measurement models, the CI development strategy focuses more on the dimensions of the organization, technology and human resources. The collaborative CI development strategy by utilizing external resources is still relatively limited. In the last decade, the strategies for developing innovation in various manufacturing industries have undergone significant changes. Today's innovation activities are becoming more open, global and carried out collaboratively (Nambisan, 2013).
Holistic model for measuring CIC 
Another challenge in measuring innovation capability is the needs for a performance measurement system and innovation capability that is able to show cause and effect relationship between the factors or elements being measured (Dewangan and Godse, 2014). Colarelli O'Connor in Björkdahl and Börjesson (2012) revealed that innovation capabilities of a company must be developed sustainably using a systemic approach, so a measurement model that can guarantee the formation of the ability to continuously innovate must be able to describe the pattern of relationships (contextual relationships) between factors or elements being measured.

\subsection{Innovation capability measurement models mapping}

Innovation capability measurement models in manufacturing industry have been developed by several researchers, employing different approaches. The results of innovation capability measurement model mapping and gap analysis are presented in Table 1.

In 1989, Schroeder et al. (1989) developed a model for measuring innovation capabilities by taking into account the characteristics of the manufacturing industry called the Framework for Manufacturing Innovation (FMI). This research was conducted in the manufacturing industry in the USA. In terms of the measurement dimensions, the factors used tend to focus only on organizational, strategic, people and financial dimensions. Measurement elements have used three main elements of innovation capability measurement, namely innovation potential, process and results innovation. The FMI model does not explain how the relationship pattern among innovation enablers is used. In 1999, Yamin et al. (1999) developed a model called the Organization Innovation Scale (OIS). OIS is a form of Innovation Index that is used to measure the innovation index at the Australian Manufacturing Company (AMC). In terms of the dimensions of measurement, the factors used are more focused on the dimensions of technology and organization. The measurement elements used are more oriented to the elements of potential and innovation results. The OIS model is a partial innovation measurement model and does not yet explain the pattern of relationships and interactions between the considered factors.

By considering the dynamic of manufacturing industries, Lawson and Samson (2001) developed an innovation capability measurement model based on dynamic capability approach, later called dynamic innovation capability (DIC). There are seven innovation capability enablers used in DIC model. This model has been applied to electronic industry Cisco. From the perspective of measurement dimensions, this model is more focused on strategy, technology, people and organization. However, DIC does not explain the relationship pattern and interaction between enablers. Another model is used to measure a company's innovation capability index, which uses resource-based perspective of the firm and was developed by Carayannis and Provance (2008), called the Composite Innovation Index (CII). This model was tested in a CII measurement on 172 innovative manufacturing firms (TOP 100 project) in Germany. In the CII model, the posture dimension will impacts the propensity dimension, which then impacts performance; but the model does not explain the interaction and relationship between enablers in one dimension, or between enablers in different dimensions.

In the context of manufacturing industries in Asia, in their research on manufacturing industries, Hong et al. (2012) introduced an innovation capability multilevel (ICM) model. This model is developed by categorizing innovation capability enablers into three levels: strategic enabler, operational enabler and innovation process. As viewed from the measurement dimension, the enablers used in ICM are more focused on strategy, organization, knowledge and financial. ICM includes a complete measurement model with three levels and eight enablers, among which strategic enablers, impact operational enablers, which in turn influence the innovation process. The model is able to define the interaction and relationship 


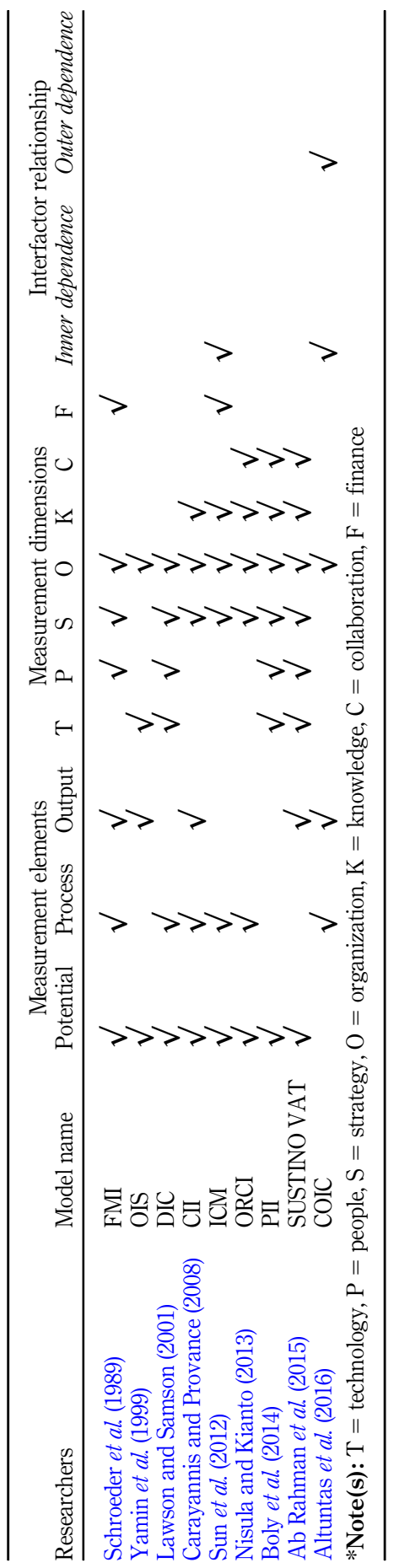

Holistic model for measuring CIC 
between enablers in one level; however, it cannot clarify the relationship between enablers in different levels. Nisula and Kianto (2013) later proposed a concept called Organizational Renewal Capability Inventory (ORCI). ORCI uses six fundamental enablers as a basis to measure capacity of renewal. The model has been applied to manufacturing industries in Finland. With respect to measurement dimensions, the innovation capability enablers used in this model are more focused on knowledge management, strategy, organization and collaboration. ORCI is a partial measurement model, and the relationship between enablers is regarded as independent. Boly et al. (2014) proposed the Potential Innovation Index (PII), which employs 15 enablers called fundamental innovation management best practices. PII has been utilized in manufacturing industries in France. The measurement dimensions in this model cover a sufficiently complete range, i.e. technology, people, strategy, organization, knowledge management and collaboration. Similar to ORCI, PII is also a partial innovation capability measurement model with independent relationships between enablers. Neither models examine the relationship pattern or interaction between enablers.

In a more comprehensive framework, Ab Rahman et al. (2015) developed a model called Sustainability of Overall Innovation Capability (SUSTINOVAT). SUSTINOVAT is a CIC measurement model using eight enablers. The model was developed and applied in manufacturing industries in Iran. With its hierarchical structure, SUSTINOVAT cannot explain the relationship and interaction between innovation capability enablers in one dimension and those in different dimensions. Altuntas et al. (2016) presented the Corporate Innovation Capability (COIC) model, in which innovation capability enablers and metrics are based on the Oslo manual, i.e. organization innovation capability, process innovation capability, product innovation capability and marketing innovation capability. Its value calculation was performed by experts' opinion using the data mining approach of fuzzy grid-based rule-mining algorithm (FGBRMA). The innovation capability enablers included in COIC are focused on technology, knowledge management and organization. Because COIC is a network model, it is able to explain relationship pattern and interaction between enablers.

\section{Research methodology}

This research consists of three stages as described below.

\subsection{Identification of manufacturing continuous innovation measures (MCIMs)}

The first stage of the study began with the identification of initial MCIMs through a systematic literature review. We followed Tranfield et al's (2003) three-stage procedure: planning, execution, and reporting. Identification of MCIMs was preformed from 78 selected papers. Selected MCIMs from literature study were further confirmed by manufacturing industry practitioners using a focus group discussion (FGD) approach. Afterward, the selection process of MCIMs was carried out using the fuzzy Delphi method (FDM). The method proposed by Hsu et al. (2010) was adopted in this study to show experts' consensus with geometric mean approach. The selection process involves an expert panel of manufacturing industry practitioners and academic experts. Academic experts and industry practitioners considered for the expert were selected based on two criteria (Hsu et al., 2017): mastery of research topics (knowledge) and work experience (skills). Based on the above criteria, 26 experts were chosen, including of 13 academic experts and 13 industry practitioners. All experts were contacted via e-mail and telephone to confirm their involvement. Then, a Google Form questionnaire containing initial MCIMs was distributed to all experts electronically. Seventeen experts completed the questionnaire, yielding a survey response rate was $65 \%$. The response rate was considered valid as it conformed to the 
requirements of data collection, of which 10-15 experts' response is considered sufficient (Manakandan et al., 2017). The experts' profile is shown in Tables 2 and 3.

\subsection{Development of measurement model}

This stage consists of four steps. It started with development of contextual relationships between MCIMs. The method used was total interpretive structural modeling (TISM). The TISM method applied in this study was adopted from the seven stages of TISM proposed by Rajesh (2017). For this step, experts were selected from the management of manufacturing industry associations, manufacturing industry think tanks and government agencies that technically manage manufacturing industries in Indonesia. The experts involved in this research stage included nine experts representing five priority manufacturing industry sectors (related to the Making Indonesia 4.0 initiative): automotive, chemical, electronic, textile and clothing, as well as food and beverages.

The weights of the MCIMs were calculated using the analytical network process (ANP) method (Saaty, 2006). The process begins with structuring the problem in the form of a network model that describes the inner and outer dependence using a validated TISM model of contextual relationships between MCIMs. The output from the TISM model has been used as a basis for the preparation of the ANP network model in several previous studies (Valmohammadi and Dashti, 2016; Dalvi-Esfahani et al., 2017). Pair-wise comparison data collection between MCIMs was conducted by four of the nine TISM industry practitioner experts. The calculation of the consistency ratio of each pair-wise comparison matrix was performed using the Super Decision version number 3.2.0 software. If the calculation results show that a paired matrix has a consistency ratio of $>10 \%$, the experts will repeat the creation of a pair-wise comparison matrix. It is then represented in a stochastic vertical and horizontal matrix forming three supermatrix stages: unweight supermatrix, weight

\begin{tabular}{lll}
\hline Experts & Position & Sector \\
\hline E1 & Engineering manager & Automotive parts \\
E2 & GM.Corp. R \& D & Food \\
E3 & R\&D manager & Pharmacy \\
E4 & Vice president & Textiles \\
E5 & Plant manager & Aluminum extrusion \\
E6 & Director & Enamel ware \\
E7 & Corporate secretary & Textiles \\
\hline
\end{tabular}

Holistic model for measuring CIC

\begin{tabular}{ll}
\hline Expert & Field of expertise \\
\hline E8 & Industrial engineering, operation's management and supply chain management \\
E9 & Industrial engineering and supply chain management \\
E10 & Industrial engineering, supply chain design and logistics' management \\
E11 & Industrial engineering and supply chain management \\
E12 & Manufacturing systems, quality management systems and supply chain management \\
E13 & Industrial engineering, system engineering and technology policies \\
E14 & Productivity, quality and manufacturing systems \\
E15 & Industrial engineering and multicriteria decision-making \\
E16 & Strategy and management of innovation \\
E17 & Industrial engineering, production system and scheduling \\
\hline
\end{tabular}


supermatrix and limit supermatrix. The final step is to calculate and determine the weights and priorities of the dimensions and MCIMs.

To develop a CIC score calculation mechanism, assessment indicators of each MCIM and criteria in each dimension were first determined. The indicators were selected based on literature studies. Factor criteria in each dimension were selected in a balanced manner, based on the measurement elements of innovation potential, innovation process and innovation results. Finally, 50 criteria and 103 indicators were used to measure the CIC score. For each MCIMs in every dimension and measurement elements, assessment criteria were set. The calculations were performed using a mathematical formula.

\subsection{Evaluation and validation of the model}

The developed model was then evaluated and validated in multiple case studies. The CIC model was applied to two manufacturing industry sectors. The companies selected as case study sites were (1) companies whose leaders had been involved in the research process, either as participants in FGD or as member of the experts' panel, (2) manufacturing companies with good performance as evidenced by certificates and awards and (3) their management team gives consent for application testing of developed model in this study. To evaluate and validate the model, two approaches were used: first, evaluation of three aspects of the model (the model development itself, its data collection and the CIC score calculation process); second, comparison of data from the calculation of CIC model with data from observations of real performance of the company (the results of the assessment from three top managers) in 2018. The data collection instrument uses a questionnaire with a score scale of $0-4(0=$ very bad; $1=$ bad; $2=$ good enough; $3=$ good; $4=$ very good $)$. Statistical test was employed for this comparison.

\section{Model development}

\subsection{Dimension, factors, elements and assessment criteria}

To develop a CIC score calculation mechanism, assessment indicators of each MCIMs and criteria in each dimension were first determined. The results are displayed in Table 4.

Technology is a very important dimension and becomes the core input in innovation capability development strategy (Berman and Hagan, 2006). Some research on innovation capabilities in the manufacturing industry shows that several factors related to technology are factors that are very influential to the development of innovation capabilities such as production capability, IT capability and R\&D capabilities. In addition to technological factors, one fundamental principle found in companies having CICs is that they are always focused on human development (Steiber, 2014). Some research on innovation capabilities in the manufacturing industry shows that people-related factors are very influential to the development of CIC, such as adaptive capability and people motivation and participation. Another dimension that is also very important is organization. One of the points of six management principles for CI put forward by Steiber (2014) is "a continuous changing organization". This principle states that organizations must constantly change and adapt to changes in the dynamic business and industrial environment. Research on innovation capabilities in the manufacturing industry also reveals that several factors related to organization and management have a positive influence on the development of innovation capabilities such as organization culture and climate, leadership, structure and system and project management skills. Previous studies have also found that the dimension of strategy plays an important role in maximizing innovation capabilities. Some factors related to the dimension of strategy include strategic capability and strategic competence. One of the factors that is also considered as part of the dimension is the dynamic capability, described as 


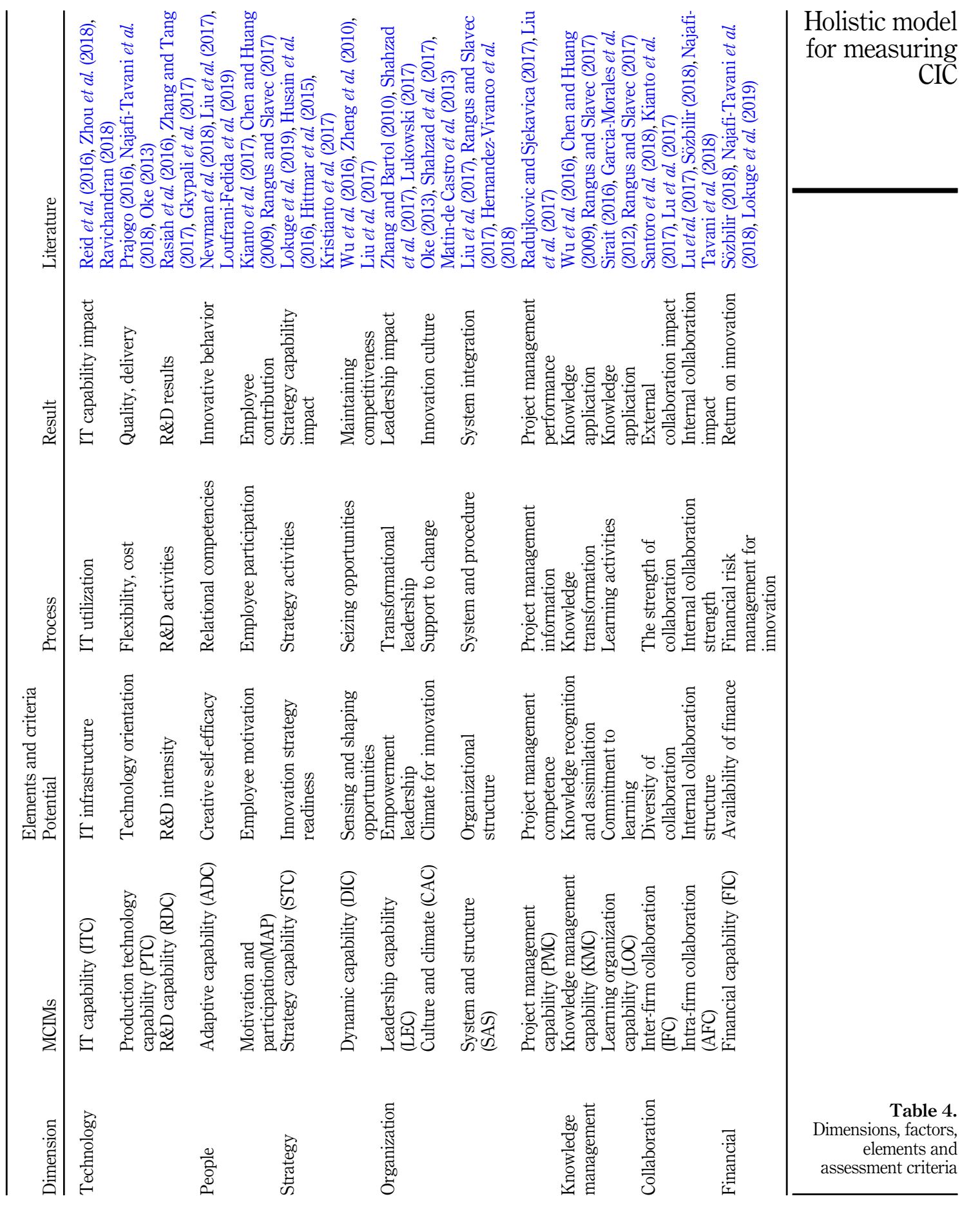


the ability of a company in integrating, developing and reconfiguring internal and external competencies when being faced with very rapid changes (Wu et al., 2016).

In a rapidly changing market in a knowledge-based economic system, the knowledge dimension plays a very central role in finding innovation opportunities. Chapman and Magnusson (2006) said that knowledge as a key component in achieving long-term continuous innovation has been widely accepted in modern innovation management. Some research on innovation capabilities in the manufacturing industry presented several factors related to knowledge management that are very influential to the development of innovation capabilities in a sustainable manner, such as: knowledge management capacity and organizational learning capability.

In the digital era that facilitates connectivity and concept shift from own economic into sharing economy, companies have great potential to conduct various innovation activities with collaborative alignment. Studies on innovation capabilities in the current manufacturing industry found several factors related to connectivity and collaborative action, both interfirm collaborative action and intrafirm collaborative action.

Financial factors are also observed to be in play. Respondents for this study provided input on how financial availability for funding the innovation activities are important and cannot be ignored.

\subsection{TISM structural model validation}

The TISM method applied in this study was adopted from the seven stages of TISM proposed by Rajesh (2017). The last step is TISM structural model validation. This validation step was performed by a TISM expert team. Each expert evaluated relationships between two MCIMs factors according to a Likert scale of $1-5$, where the value of 1 indicates that the experts strongly disagree with the relationship between two factors evaluated and a value of 5 means the that experts are in substantial agreement. If the average scale is $3(60 \%)$, the relationship between factors is then regarded as "acceptable". Meanwhile, if the average scale is below $60 \%$, the relationship will be "rejected" from the diagram. The final result of expert validation that showing the accepted relationship between MCIMs is presented in Table 5.

\subsection{The weight of dimension and priority of MICMs}

The weights of the MCIMs were calculated using the ANP method. The overall result is presented in Table 6.

\subsection{Calculation mechanism for CICs score}

The CIC score was calculated using a mathematical formula adopted from a multifactor model developed by Sahay (2004). The calculation was initiated by determining the score of each indicator in every criterion for each MCIMs. The score for the indicators was obtained from the respondent's assessment of the corresponding indicator in their company. The formula used to calculate the score for each criterion is as follows:

$$
\mathrm{SC}_{i, j, k}=\sum_{l=1}^{q} \mathrm{SI}_{i, j, k, l} \mathrm{WI}_{i, j, k, l}
$$

where

$q=$ number of indicators for $k$-criterion on $j$-factor in $i$-dimension

$\mathrm{SI}_{i, j, k, l}=$ score of indicator number $i$, for $k$-criterion on $j$-factor in $i$-dimension

$\mathrm{WI}_{i, j, k, l}=$ weight of indicator number $i$, for $k$-criterion on $j$-factor in $i$-dimension 


\begin{tabular}{llllllll}
\hline$i$ & Relation & $j$ & Mean & $i$ & Relation & $j$ & Mean \\
\hline ITC & $\mathrm{V}$ & ADC & 4.33 & MAP & A & CAC & 3.56 \\
ITC & $\mathrm{V}$ & DIC & 3.56 & MAP & X & LOC & 3.11 \\
ITC & A & LEC & 4.33 & MAP & A & FIC & 3.22 \\
ITC & X & SAS & 4.22 & STC & A & LEC & 3.33 \\
ITC & V & LOC & 4.11 & STC & X & AFC & 3.33 \\
ITC & V & IFC & 4.22 & DIC & A & LEC & 3.67 \\
ITC & V & AFC & 3.89 & DIC & X & SAS & 3.22 \\
PTC & A & LEC & 3.56 & DIC & X & IFC & 3.22 \\
PTC & X & FIC & 3.22 & LEC & V & CAC & 3.89 \\
RDC & X & ADC & 3.33 & LEC & V & SAS & 4.11 \\
RDC & A & MAP & 3.67 & LEC & V & LOC & 3.56 \\
RDC & A & LEC & 4.22 & LEC & V & IFC & 3.67 \\
RDC & A & PMC & 3.56 & LEC & V & AFC & 3.44 \\
RDC & X & ICC & 3.44 & LEC & V & FIC & 4.11 \\
RDC & A & FIC & 3.33 & CAC & V & SAS & 3.89 \\
ADC & A & MAP & 3.67 & CAC & V & LOC & 3.33 \\
ADC & A & LEC & 3.78 & CAC & V & AFC & 3.33 \\
ADC & A & CAC & 3.67 & SAS & X & AFC & 3.33 \\
ADC & X & SAS & 3.44 & KMC & X & LOC & 3.67 \\
ADC & X & LOC & 3.44 & LOC & X & IFC & 3.56 \\
ADC & X & IFC & 3.67 & ECC & X & FIC & 3.44 \\
MAP & A & LEC & 4.00 & & & & \\
\hline
\end{tabular}

Holistic model for measuring validation

\begin{tabular}{|c|c|c|c|c|c|}
\hline Dimension & $\begin{array}{c}\text { Dimension } \\
\text { weight }\end{array}$ & MCIMs & $\begin{array}{l}\text { Global } \\
\text { weight }\end{array}$ & Priority & \\
\hline \multirow[t]{3}{*}{ Technology } & \multirow[t]{3}{*}{0.1505} & IT capabilities & 0.0804 & 0.5343 & \\
\hline & & Production capability & 0.0243 & 0.1615 & \\
\hline & & R\&D capability & 0.0458 & 0.3041 & \\
\hline \multirow[t]{2}{*}{ People } & \multirow[t]{2}{*}{0.2051} & Adaptive capability & 0.0570 & 0.2781 & \\
\hline & & Motivation and participation & 0.1481 & 0.7219 & \\
\hline \multirow[t]{2}{*}{ Strategy } & \multirow[t]{2}{*}{0.0252} & Strategic capability & 0.0092 & 0.3640 & \\
\hline & & Dynamic capability & 0.0160 & 0.6360 & \\
\hline \multirow[t]{4}{*}{ Organization } & \multirow[t]{4}{*}{0.3936} & Leadership & 0.1650 & 0.4193 & \\
\hline & & Culture and climate & 0.1024 & 0.2601 & \\
\hline & & Project management & 0.0467 & 0.1185 & \\
\hline & & Structure and system & 0.0795 & 0.2020 & \\
\hline \multirow[t]{2}{*}{$\begin{array}{l}\text { Knowledge } \\
\text { management }\end{array}$} & \multirow[t]{2}{*}{0.0776} & $\begin{array}{l}\text { Knowledge management } \\
\text { capacity }\end{array}$ & 0.0286 & 0.3686 & \\
\hline & & Learning capability & 0.0490 & 0.6313 & \\
\hline \multirow{2}{*}{ Collaboration } & \multirow{2}{*}{0.0699} & Interfirm collaboration & 0.0319 & 0.4559 & Table 6. \\
\hline & & Intrafirm collaboration & 0.0380 & 0.5440 & Weight of dimension \\
\hline Financial & 0.0779 & Financing capability & 0.0779 & 1.0000 & and priority of MICMs \\
\hline
\end{tabular}


After all the criteria scores were calculated, the MCIMs factor scores were calculated using the following formula:

$$
\mathrm{SF}_{i, j}=\sum_{k=1}^{s} \mathrm{SC}_{i, j, k} * \mathrm{WC}_{i, j, k}
$$

where:

$s=$ number of criteria on the $j$-factor in the $i$-dimension

$\mathrm{SF}_{i, j}=$ score of $j$-factor on the $i$-dimension

$\mathrm{SC}_{i, j, k}=k$-criterion score on the $j$-factor in the $i$-dimension

$\mathrm{WC}_{i, j, k}=k$-criterion weight on the $j$-factor in the $i$-dimension

Next, the dynamic impact of MICMs on a related factor was determined using this approach:

(1) Calculate differences in scores for factors with relationships (see Table 5). For example, if a factor with $R 1$ relationship impacts $R 2$, the difference in scores (delta) between $R 1$ and $R 2$ can be calculated using the following formula:

$$
\text { Delta }=\mathrm{SF}[R 1]-\mathrm{SF}[R 2]
$$

(2) Calculate R2 score after being impacted by R1 with the following formula:

$$
\mathrm{SF}[R 2]=\mathrm{SF}[R 2]+\operatorname{Delta} * \operatorname{Mean}(R 1, R 2)
$$

The basic concept of the aforementioned approach came from Ohm's law, of which an organization as an integrated system is projected as similar to an electric circuit (Härtel, 2007). Ohm's law states that "the current or electricity passing through a conductor is directly proportional to voltage or potential difference, and inversely proportional to the resistance of the circuit $(\mathrm{I}=\mathrm{V} / \mathrm{R})$ ". In this study, the dynamic impact of an MCIMs was depicted as current, and the score difference represented the voltage. The relationship means between MICMs was regarded as the resistance. If the relationship mean was high, the resistance would be small and vice versa. The $R 2$ score was then calculated by adding the previous $R 2$ score to the current (I) from its impacting MCIMs. To obtain I, the score difference between factors was multiplied by the relationship mean between factors. When all relationship impact between factors had been calculated, and the factor score had achieved a stable condition, the score for each dimension was calculated using the following formula:

$$
\mathrm{SD}_{i}=\sum_{j=1}^{p_{i}} \mathrm{SF}_{i, j} * \mathrm{WF}_{i, j}
$$

The $\mathrm{CIC}_{\text {score }}$ was then calculated by:

$$
\mathrm{CIC}_{\text {score }}=\sum_{i=1}^{r} \mathrm{SD}_{i} * \mathrm{WD}_{i}
$$

where,

$$
\begin{aligned}
& r=\text { number of dimensions } \\
& i=\{1 \ldots r\} \\
& \mathrm{SD}_{i}=\text { score in } i \text {-dimension }
\end{aligned}
$$


$p_{i}=$ number of factors in $i$-dimension

Holistic model

$\mathrm{SF}_{i, j}=$ score of $j$-factor in $i$-dimension

$\mathrm{WF}_{i, j}=$ weight of $j$-factor in $i$-dimension

The framework of the comprehensive model of CIC measurement is shown in Figure 1. The model framework clearly shows the relationships between MCIMs factors along with the data on the mean magnitude of relations between factors (sourced from Table 5). The thick lines indicate the strength of the relationship between MCIMs. The results of the MCIMs factor score calculation and dimension score are displayed thoroughly, so that it can be seen which factors and dimensions influence the total CIC score.

From the model above, CIC score is influenced by seven dimensions: technology, people, strategy, organization, knowledge management, collaboration and financial. Each dimension score is influenced by the MCIMs factor score. Figure 1 depicts contextual relationship between MCIMs. Information technology capabilities greatly affect adaptive capabilities of HR with a relationship mean of 4.33 (scale 1-5). In addition, information technology capabilities are strongly influenced by leadership capabilities with a relationship mean of 4.33. Information technology capabilities also have a very strong mutually influencing relationship with system capabilities and organizational structures. Information technology capabilities have a very strong influence on the external collaboration capabilities of the company (interfirm collaboration).

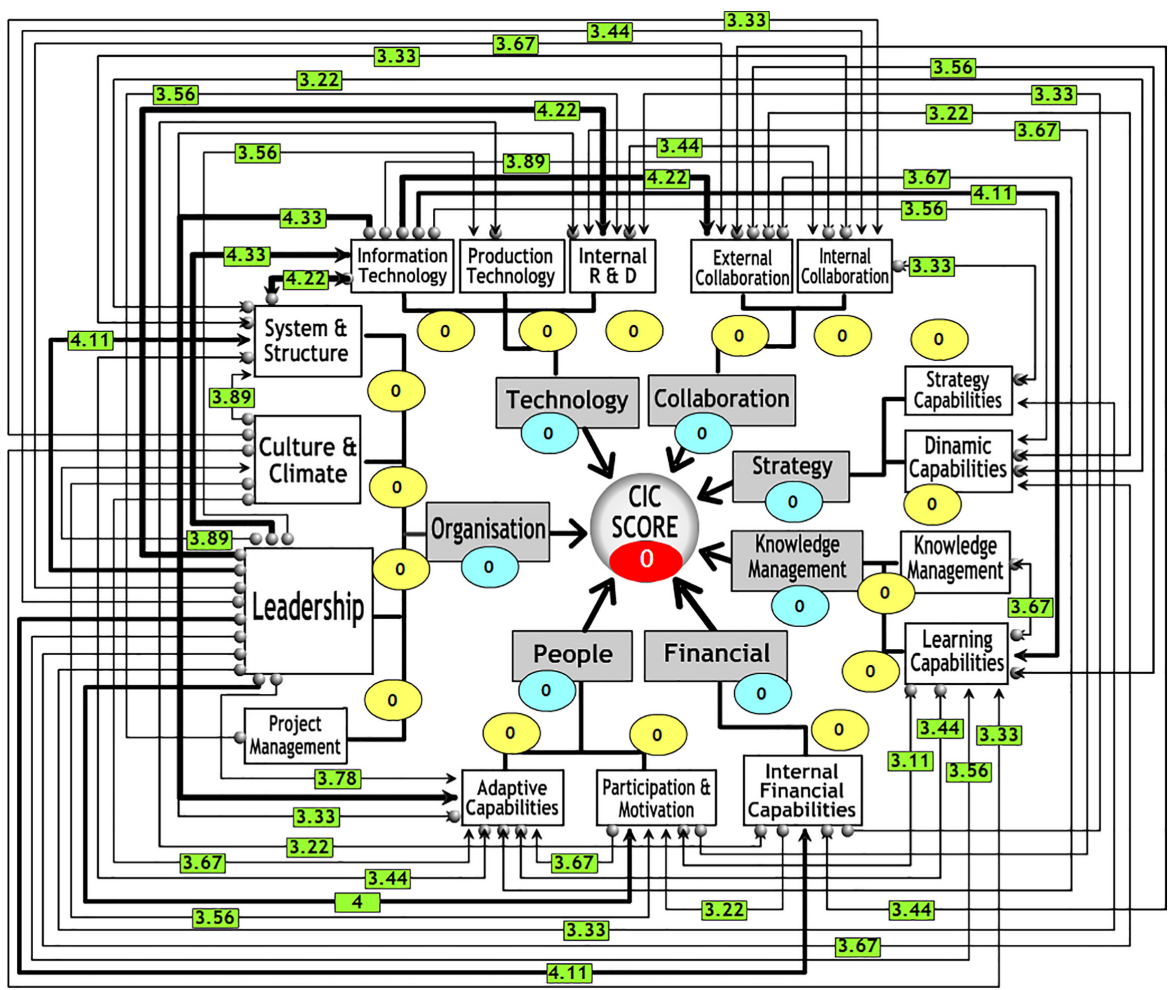

Figure 1. CIC model framework 
To determine performance level of $\mathrm{CIC}$ scores, the interval between $\mathrm{CIC}$ s was calculated. The highest value in the scores measurement was 4 , and the lowest was 0 . Thus, the interval for performance rating was 0.8 , as presented in Table 7 .

\section{Case study}

CIC model assessment was performed in two case studies: the automotive company (denoted as Case Study 1) and electronics company (Case Study 2). Multiple case studies were conducted to evaluate and validate current assessment model. The informants or respondents involved in these case studies are displayed in Table 8.

CS1 was performed in a company manufacturing automotive spare parts, mainly automatic gaskets. The company was founded in 1983 in Surabaya, East Java, Indonesia. Approximately $95 \%$ of the products are marketed domestically, and 5\% are exported. The manufacturing facility sits on an area of $9,000 \mathrm{~m}^{2}$. The company employs 400 workers and has distribution offices in 12 cities across the country.

CS2 was performed in a company manufacturing electronics, located in Sidoarjo, East Java, Indonesia. The company was founded in 1970 and currently has approximately 1,000 employees. Since its early establishment, the company has collaborated with many global companies such as JVC, Maxell, TEAC, JBL, GE, Unilever, ZTE and Huawei.

Based on evaluations from respondents conducted during data collection, the currently developed CIC model received good feedback (see Table 9).

The results of CIC model evaluation for both case studies indicated good feedback: Most respondents strongly agreed that the model was easy to understand, the data required could be obtained in a straightforward manner and the CIC score calculation process was well understood.

Model validation was then conducted by comparing the total score calculated by CIC model and the actual score from observation results in 2018. The indicator score value given by the respondent in case study was then inputed into the CIC measurement model to calculate the criteria score, CIC in 2018 factor score, dimension score and total score with the

\begin{tabular}{ll}
\hline Interval & CIC's performance \\
\hline $0.00-0.80$ & Worst \\
$0.81-1.60$ & Bad \\
$1.61-2.40$ & Fair \\
$2.41-3.20$ & Good \\
$3.21-4.00$ & Very good
\end{tabular}

\begin{tabular}{lcc}
\hline Job title & Case study 1(CS1) & Case study 2(CS2) \\
\hline President director & 1 & 1 \\
Director/plant manager & 2 & 2 \\
Production/manufacturing/engineering manager & 3 & 2 \\
Finance manager & 1 & 1 \\
Human resources manager & 1 & 1 \\
R\&D manager & 1 & 1 \\
Marketing manager & 1 & 4 \\
Employee (senior and junior) & 6 & 4 \\
\hline
\end{tabular}

Table 8.

Summary of respondents for case studies 
help of CIC Pro Ver.1.0 software. Meanwhile, actual data from observations by the three top management of case study's company were collected. The following is comparison of CIC score from the model and actual data from the observations (see Table 10).

Two-way ANOVA test using SPSS software was then employed for validation, performed in the following steps:

(1) Testing data normality

Data normalization testing was conducted using the Kolmogorov-Smirnov test method, with the following hypothesis formulations:

HO. The data follow a normal distribution.

H1. The data do not follow the normal distribution, for each corresponding year.

Reject H0 if the $p$-value $<0.05$.

From Figures 2 and 3 , it is evident that $p$-value $>0.05$. It can be concluded that all variables follow normal distribution.

(2) Two-way ANOVA test

To calculate the difference of CIC scores from the model and from managers' observations, two-way ANOVA was used with the following formulations:

Hypothesis

HO. No difference between CIC total score and average TM score.

H1. There is difference between CIC total score and average TM score.

By considering study condition in which data collected based on limited respondent numbers, thus $\alpha$ was set at $10 \%$. With $p$-value $=0.882$, reject $\mathrm{H} 0$ was fulfilled. It can be concluded that there is no difference between total CIC score from the model and from top managers'

\begin{tabular}{|c|c|c|c|c|c|c|c|}
\hline \multirow[b]{2}{*}{ Aspects } & \multicolumn{2}{|c|}{ Strongly agree } & \multicolumn{2}{|c|}{ Agree } & \multicolumn{2}{|c|}{$\begin{array}{l}\text { Neither agree nor } \\
\text { disagree }\end{array}$} & \\
\hline & CS1 $(\%)$ & $\mathrm{CS} 2(\%)$ & $\mathrm{CS} 1(\%)$ & CS2 $(\%)$ & $\mathrm{CS} 1(\%)$ & $\mathrm{CS} 2(\%)$ & \\
\hline Ease in understanding the approach & 75 & 84.62 & 25 & 15.38 & & & \\
\hline Ease in data collection & 62.5 & 76.92 & 31.35 & 23.08 & 6.25 & & Table 9. \\
\hline $\begin{array}{l}\text { Ease in understanding CIC score } \\
\text { calculation }\end{array}$ & 81.25 & 69.23 & 18.75 & 15.38 & & 15.39 & $\begin{array}{r}\text { Evaluation of currently } \\
\text { developed model }\end{array}$ \\
\hline
\end{tabular}

\begin{tabular}{|c|c|c|c|c|c|c|c|c|c|c|c|}
\hline \multirow[b]{3}{*}{ Dimension } & \multirow{2}{*}{\multicolumn{4}{|c|}{ Average }} & \multicolumn{6}{|c|}{ Top managers (TM) } & \\
\hline & & & & & & CS1 & & & CS2 & & \\
\hline & CS1 & CS2 & $\mathrm{CS} 1$ & CS2 & TM1 & TM2 & TM3 & TM1 & TM2 & TM3 & \\
\hline Technology & 2.23 & 2.77 & 2.33 & 2.83 & 3 & 2 & 2 & 3 & 3 & 2.5 & \\
\hline People & 2.46 & 2.85 & 2.67 & 3.00 & 3 & 3 & 2 & 3 & 3 & 3 & \\
\hline Strategy & 2.22 & 2.86 & 2.17 & 3.00 & 2.5 & 2 & 2 & 3 & 3 & 3 & \\
\hline Organization & 2.48 & 2.97 & 2.33 & 3.00 & 3 & 2 & 2 & 3 & 3 & 3 & \\
\hline Knowledge management & 2.30 & 2.66 & 2.33 & 2.67 & 3 & 2 & 2 & 3 & 2 & 3 & Table 10. \\
\hline Collaboration & 2.22 & 2.89 & 2.00 & 3.00 & 2 & 2 & 2 & 3 & 3 & 3 & Comparisons of CIC \\
\hline Financial & 2.31 & 2.80 & 2.33 & 2.67 & 3 & 2 & 2 & 3 & 3 & 2 & scores from model and \\
\hline Total CIC score & 2.38 & 2.87 & 2.33 & 3.00 & 3 & 2 & 2 & 3 & 3 & 3 & from observation \\
\hline
\end{tabular}




\section{IJPPM}

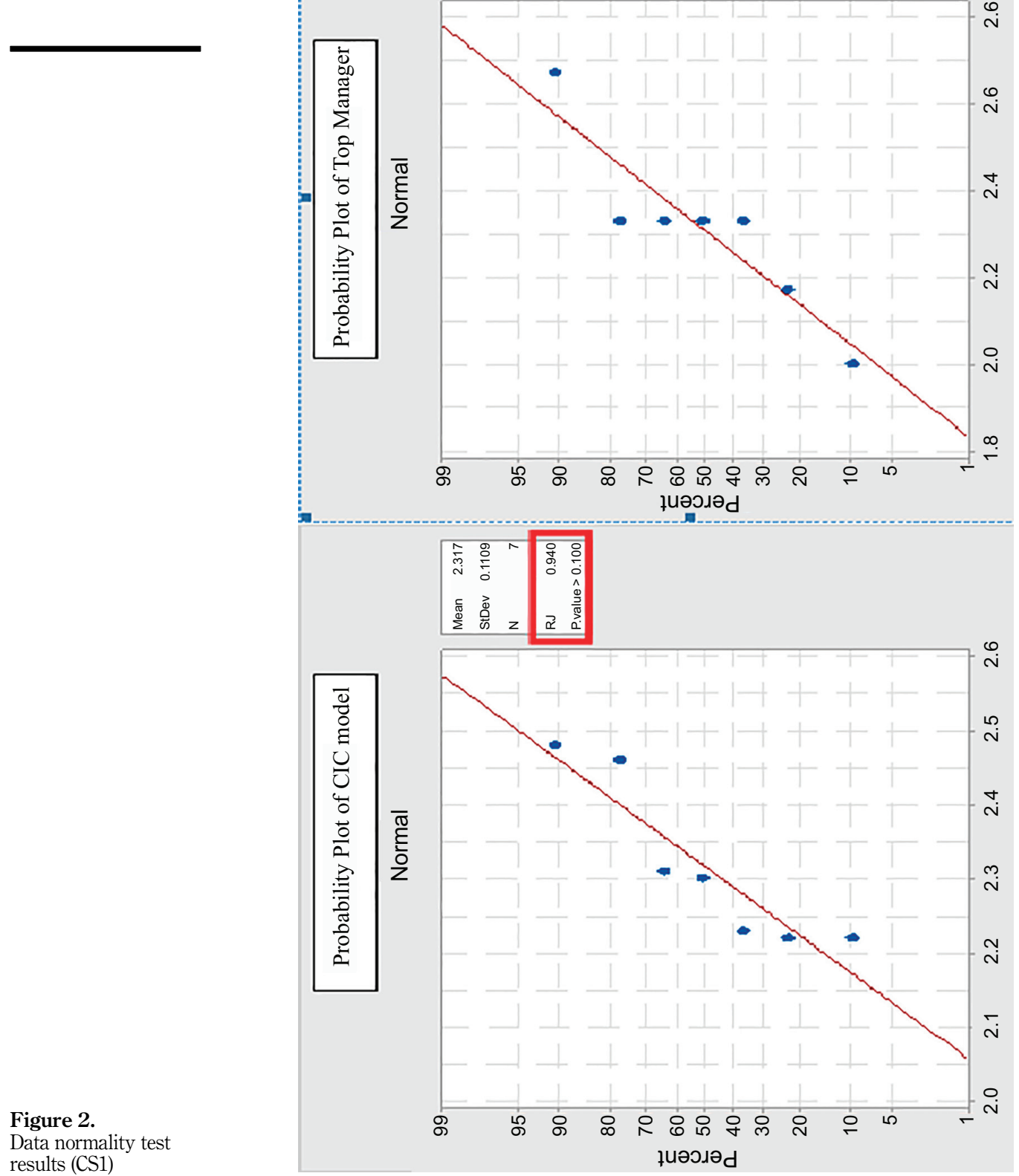


Holistic model

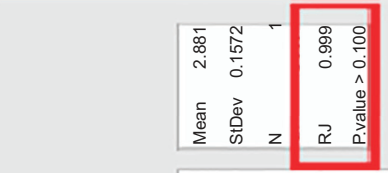

for measuring CIC
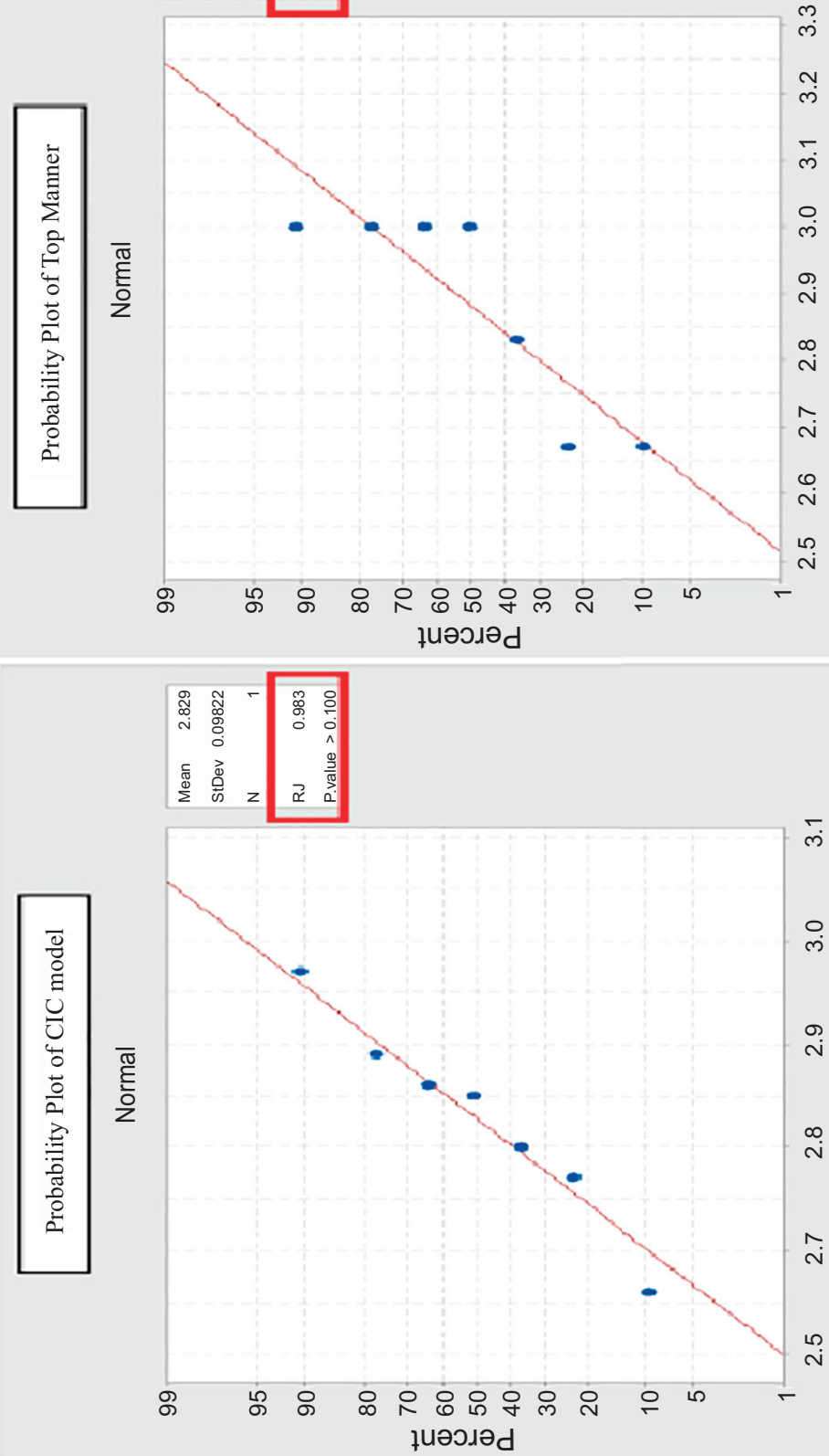

Figure 3. Data normality test results (CS2) 
observations (CS1) and with $p$-value $=0.198$, then it was failed to reject $\mathrm{H} 0$. The results of this test indicated that in general there is no difference between the total CIC score and the total TM score (CS2) (see Table 11).

\section{Discussion}

With the disruptive trend of Industry 4.0 and of the fast-changing industrial environment, firms in the manufacturing industry require a comprehensive and holistic, inclusive framework to measure their ability to innovate continuously, which will assist them in managing their innovation activities systematically and comprehensively. With such a framework, a company can track its innovation capability and determine areas for improvement, as well as map strategic decisions to enhance their CIC (Phan, 2013).

This study aims to develop a holistic CIC model for the manufacturing industry. Compared to previous measurement models, CIC model developed in this study possesses several advantages:

First, this CIC model is a holistic and inclusive; it is able to explain contextual relationship between MCIMs. Dewangan and Godse (2014) mentioned that a comprehensive and holistic measurement system of innovation capability and performance must be able to show cause and effect relationship between measured factors or elements. The description of contextual relationships between MCIMs factors will greatly assist a company in managing its innovation activities in a systematic and integrated manner. Manufacturing industry managers are in a position to see the big picture of business process; thus, they can track the company's capabilities in innovation and determine which areas are in need for improvement. They also know what strategic decisions should be made to improve innovation capabilities in a sustainable manner (Phan, 2013). In general, we found in this study that leadership, climate and culture and IT capability were very dominant MCIMs factor. Second, this CIC model concerns balanced and comprehensive measurement elements. The developed CIC was successfully implemented to combine innovation potential, processes and its results in a balanced and integrated cycle. When appropriately maintained for the long term, the cycle will contribute to the ability to continuously innovate. Various models for measuring the company's innovation capability have been developed which focus on different elements. Third, CIC model measure a balanced way the innovation capability of every critical dimension in a company based on six management principles of CI (Steiber, 2014) and six strategies for developing CI, i.e. technology, people, strategy, organization and system, knowledge management and collaboration (Lianto et al., 2018); moreover, it includes an additional dimension, finance, as suggested by manufacturing industry practitioners in Indonesia.

This CIC model also attempts to propose a collaborative CI development strategy by leveraging external resources as an important thing that needs to be improved. Nambisan (2013) stated that innovation activity in the fourth industrial revolution era will become more open, global and done collaboratively. Thus, the innovation performance of a company is no longer only dependent on the company's internal sources of knowledge and technology but also needs to be equipped with external sources of knowledge and technology obtained through the company's ability to build linkages with various external parties. The results of CIC score measurement in case study companies show that the company is still weak in developing collaboration capabilities to improve innovation capabilities. Most innovation activities rely solely on internal resources. The implementation of the CIC model demands the manufacturing industry to be a more open company and to network and collaborate with various external parties. In addition, for long, innovation is often seen as a linear model, such as technology-push models; where the process of development, production and marketing of a product/technology is a sequential process initiated by research activities. However, in 
Holistic model
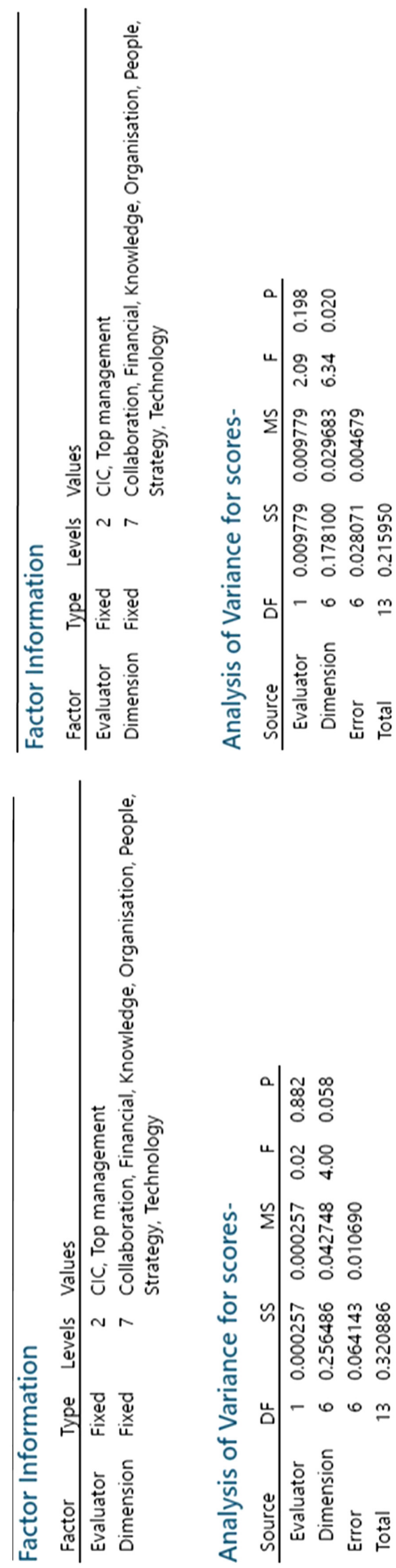

Table 11.

Test results for $\mathrm{CIC}$ scores from model and from observations (CS1 and CS2) 
today's landscape, innovation is not only a process or stage of product development but also closely related to company's ability to interact, learn collectively and build trusting relationships with all innovation partners (Ukko et al., 2016). The results of this study support and complement the results of previous research. In the face of the industrial era 4.0, the manufacturing industry should not only focus on the development of production technology, which is relatively expensive and requires large investments, but also on how to develop adaptive capabilities and learning of human resources, motivation and participation of human resources, culture and innovation climate, leadership capabilities, information technology capabilities and the ability to build effective collaboration.

The CIC measurement model developed in this study can be utilized as self-assessment tool and the measurement results can be used as a positioning for companies to measure progress over time. The score range and performance level of the CIC model are as follows: 0.00-0.80 (very poor, performance level 0). The score indicates no innovation initiatives, and companies are not ready to innovate. Some of the hallmarks of the company's condition are as follows: There is absolutely no initiative or planning for innovation activities, no special sections or parties are responsible for the development of innovation and there is absolutely no evidence of supporting documents. Score range of 0.81-1.60 (bad, performance level 1) suggests there have been innovation initiatives but are not routine and unstructured. Score range of 1.61-2.40 (good enough, performance level 2) indicates there has been an innovation initiative, in a structured way but it hasn't gone well. Score range of 2.41-3.20 (well, performance level 3) denotes that the innovation activities and processes are running well and routinely but the results are not yet maximized. The next score range of 3.21-4.00 (excellent, performance level 4) highlights that the innovation activities and processes have been running very well, structured and routine and provide maximum results. One of distinguished characteristics of high-performing companies is the existence of planning, implementation, evaluation, control and periodical improvement against every innovation activity.

\subsection{Theoretical contribution}

This study delivered more comprehensive and holistic measurement and assessment of CICs by considering current landscape of Indonesia's manufacturing industry. The CIC model could address the limitation of most CIC measurement models which mainly focus on singledimension measurements or partial measurements or of those lacking a systemic approach and less-holistic perspectives. This model is a new holistic measurement model; it integrates three fundamental elements of CI capability measurement, considering all important dimensions in a company and also able to explain contextual relationships between measured factors. On the other hand, CIC model developed in this study also assists in mapping measurement criteria in each element, thus forming a complete, balanced and integrated cycle.

\subsection{Practical implication}

Practical implication from this study is providing insights for manufacturing industry players and the government on how to develop and improve CIC with more holistic approach. A company should develop its innovation potential seriously if they want the innovation process to be well-implemented and to produce expected innovation results. When a good innovation result is not supported by sufficient potential and a well-implemented process, the sustainability of the result is in question. On the other hand, in order to develop CI, the government and business players should utilize a multidimensional approach, considering all important the dimensions in a company and observe carefully the contextual relationships between measured factors. 
6.3 Limitations and scope for future work

This study has several limitations as follows: The CIC measurement model could be used as a self-assessment tool, with the results being a positioning insight and not for a comparative reason. Further study could focus on developing an agreed, acknowledged measurement standard for the purpose of comparison.

Assessment matrix for CIC in this study is applied to all indicators, criterion factors and dimensions. The following study could develop assessment matrix tailored to each indicators but should also consider its practical application and ease in implementation for business players.

\section{Conclusions}

The CIC model developed in this research is a holistic measurement model; compared to previously developed models, this model is able to integrate three fundamental elements of CI capability measurement namely: potential, process and results of innovation and it is multidimensional, considering all important the dimensions in a company. The model is also able to explain contextual relationships between measured factors. This CIC model could address the limitation of most CIC measurement models which mainly focus on single dimension measurements, partial measurements, lacking a systemic approach and have yet to observe innovation with a holistic approach. This research produced 50 criteria and 103 assessment indicators as well as a mathematical model to measure CIC scores. The model evaluation and validation were performed in two case studies, in the automotive and electronic industries. Trial results show that CIC measurement model in this study is valid and sufficiently accepted by manufacturing industry players in both case studies.

\section{References}

Ab Rahman, M.N., Doroodian, M., Kamarulzaman, Y. and Muhamad, N. (2015), "Designing and validating a model for measuring sustainability of overall innovation capability of small and medium-sized enterprises", Sustainability (Switzerland), Vol. 7 No. 1, pp. 537-562, doi: 10.3390/ su7010537.

Altuntas, S., Dereli, T. and Kusiak, A. (2016), "Assessment of corporate innovation capability with a data-mining approach: industrial case studies”, Computers and Industrial Engineering, Vol. 102, pp. 58-68, doi: 10.1016/j.cie.2016.10.018.

Bellamy, M.A., Ghosh, S. and Hora, M. (2014), "The influence of supply network structure on firm innovation", Journal of Operations Management, Vol. 32 No. 6, pp. 357-373, doi: 10.1016/j.jom. 2014.06.004.

Berman, S.J. and Hagan, J. (2006), "How technology-driven business strategy can spur innovation and growth”, Strategy and Leadership, Vol. 34 No. 2, pp. 28-34, doi: 10.1108/10878570610700848.

Björkdahl, J. and Börjesson, S. (2012), “Assessing firm capabilities for innovation”, International Journal of Knowledge Management Studies, Vol. 5 Nos 1-2, pp. 171-184, doi: 10.1504/IJKMS.2012.051970.

Boer, H., Caffyn, S., Corso, M., Coughlan, P., Gieskes, J., Magnusson, M., Pavesi, S. and Ronchi, S. (2001), "Knowledge and continuous innovation the CIMA methodology", International Journal of Operations and Production Management, Vol. 21 No. 4, pp. 490-503, doi: 10.1108/ 01443570110381390.

Boly, V., Morel, L., Assielou, N.G. and Camargo, M. (2014), "Evaluating innovative processes in French firms: methodological proposition for firm innovation capacity evaluation", Research Policy, Vol. 43 No. 3, pp. 608-622, doi: 10.1016/j.respol.2013.09.005.

Carayannis, E.G. and Provance, M. (2008), "Measuring firm innovativeness: towards a composite innovation index built on firm innovative posture, propensity and performance attributes", International Journal of Innovation and Regional Development, Vol. 1 No. 1, p. 90, doi: 10.1504/ ijird.2008.016861.
Holistic model for measuring CIC 
Chapman, R.L. and Magnusson, M.G. (2006), "Continuous innovation, performance and knowledge management: an introduction”, Knowledge and Process Management, Vol. 13 No. 3, pp. 129-31, doi: $10.1002 / \mathrm{kpm}$.

Chen, C.J. and Huang, J.W. (2009), "Strategic human resource practices and innovation performance the mediating role of knowledge management capacity", Journal of Business Research, Vol. 62 No. 1, pp. 104-114, doi: 10.1016/j.jbusres.2007.11.016.

Chutivongse, N. and Gerdsri, N. (2018), "Creating an innovative organization: analytical approach to develop a strategic roadmap guiding organizational development", Journal of Modelling in Management, Vol. 15 No. 1, pp. 50-88, doi: 10.1108/JM2-05-2018-0067.

Dalvi-Esfahani, M., Ramayah, T. and Nilashi, M. (2017), "Modelling upper echelons' behavioural drivers of green IT/IS adoption using an integrated interpretive structural modelling - analytic network process approach", Telematics and Informatics, Vol. 34 No. 2, pp. 583-603, doi: 10.1016/ j.tele.2016.10.002.

Delgado-Verde, M., Martín-de Castro, G., Navas-López, J.E. and Al, E. (2011), "Organizational knowledge assets and innovation capability: evidence from Spanish manufacturing firms", Journal of Intellectual Capital, Vol. 12 No. 1, pp. 5-19, doi: 10.1108/14691931111097890.

Dewangan, V. and Godse, M. (2014), "Towards a comprehensive enterprise innovation performance measurement system”, Technovation, Vol. 34 No. 9, pp. 536-545, doi: 10.1016/j.technovation. 2014.04.002.

Edison, H., Bin Ali, N. and Torkar, R. (2013), "Towards innovation measurement in the software industry”, Journal of Systems and Software, Vol. 86 No. 5, pp. 1390-1407, doi: 10.1016/j.jss.2013. 01.013 .

García-Morales, V.J., Jiménez-Barrionuevo, M.M. and Gutiérrez-Gutiérrez, L. (2012), “Transformational leadership influence on organizational performance through organizational learning and innovation", Journal of Business Research, Vol. 65 No. 7, pp. 1040-1050, doi: 10.1016/j.jbusres. 2011.03.005.

Gkypali, A., Filiou, D. and Tsekouras, K. (2017), "R\&D collaborations: is diversity enhancing innovation performance?”, Technological Forecasting and Social Change, Vol. 118, pp. 143-152, doi: 10.1016/j.techfore.2017.02.015.

Härtel, H. (2007), "The electric circuit as a system: a new approach", European Journal of Science Education, Vol. 4 No. 1, pp. 45-55, doi: 10.1080/0140528820040106.

Hernandez-Vivanco, A., Bernardo, M. and Cruz-Cázares, C. (2018), "Sustainable innovation through management systems integration", Journal of Cleaner Production, Vol. 196, pp. 1176-1187, doi: 10.1016/j.jclepro.2018.06.052.

Hittmar, S., Varmus, M. and Lendel, V. (2015), "Proposal of evaluation system for successful application of innovation strategy through a set of indicators", Procedia Economics and Finance, Vol. 26 No. 15, pp. 17-22, doi: 10.1016/s2212-5671(15)00796-0.

Hong, J., Hong, S., Wang, L., Xu, Y. and Zhao, D. (2015), "Government grants, private R\&D funding and innovation efficiency in transition economy", Technology Analysis and Strategic Management, Vol. 27 No. 9, pp. 1068-1096, doi: 10.1080/09537325.2015.1060310.

Hsu, Y.L., Lee, C.H. and Kreng, V.B. (2010), "The application of Fuzzy Delphi Method and fuzzy AHP in lubricant regenerative technology selection", Expert Systems with Applications, Vol. 37 No. 1, pp. 419-425, doi: 10.1016/j.eswa.2009.05.068.

Hsu, C.H., Chang, A.Y. and Luo, W. (2017), "Identifying key performance factors for sustainability development of SMEs - integrating QFD and fuzzy MADM methods", Journal of Cleaner Production, Vol. 161, pp. 629-645, doi: 10.1016/j.jclepro.2017.05.063.

Husain, Z., Dayan, M. and Benedetto, D.C.A. (2016), "The impact of networking on competitiveness via organizational learning, employee innovativeness, and innovation process: a mediation model", Journal of Engineering and Technology Management - JET-M, Vol. 40, pp. 15-28, doi: 10.1016/j. jengtecman.2016.03.001. 
Javahernia, A. and Sunmola, F. (2017), "A simulation approach to innovation deployment readiness assessment in manufacturing", Production and Manufacturing Research, Vol. 5 No. 1, pp. 81-89, doi: 10.1080/21693277.2017.1322542.

Kianto, A., Sáenz, J. and Aramburu, N. (2017), "Knowledge-based human resource management practices, intellectual capital and innovation", Journal of Business Research, Vol. 81 December 2016, pp. 11-20, doi: 10.1016/j.jbusres.2017.07.018.

Kristianto, Y., Gunasekaran, A. and Helo, P. (2017), "Building the 'Triple R' in global manufacturing", International Journal of Production Economics, Vol. 183, pp. 607-619, doi: 10.1016/j.ijpe.2015.12.011.

Lawson, B. and Samson, D. (2001), "Developing innovation capability in organisations: a dynamic capabilities approach", International Journal of Innovation Management, Vol. 5 No. 3, pp. 377-400, doi: 10.1142/s1363919601000427.

Lianto, B., Dachyar, M. and Soemardi, T.P. (2018), "Continuous innovation: a literature review and future perspective", International Journal on Advanced Science, Engineering and Information Technology, Vol. 8 No. 3, pp. 771-779.

Liu, X., Huang, Q., Dou, J. and Zhao, X. (2017), “The impact of informal social interaction on innovation capability in the context of buyer-supplier dyads", Journal of Business Research, Vol. 78, pp. 314-322, doi: 10.1016/j.jbusres.2016.12.027.

Lokuge, S., Sedera, D., Grover, V. and Dongming, X. (2019), "Organizational readiness for digital innovation: development and empirical calibration of a construct", Information and Management, Vol. 56 No. 3, pp. 445-461, doi: 10.1016/j.im.2018.09.001.

Loufrani-Fedida, S., Hauch, V. and Elidrissi, D. (2019), "The dynamics of relational competencies in the development of born global firms: a multilevel approach", International Business Review, Vol. 28 No. 2, pp. 222-237, doi: 10.1016/j.ibusrev.2018.09.001.

Lu, P., Yuan, S. and Wu, J. (2017), "The interaction effect between intra-organizational and interorganizational control on the project performance of new product development in open innovation”, International Journal of Project Management, Vol. 35 No. 8, pp. 1627-1638, doi: 10. 1016/j.jproman.2017.09.009.

Lukowski, W. (2017), "The impact of leadership styles on innovation management", Marketing of Scientific and Research Organizations, Vol. 24 No. 2, pp. 105-136, doi: 10.14611/minib.24.06. 2017.12.

Manakandan, S.K., Ismai, R., Jamil, M.R.M. and Ragunath, P. (2017), "Pesticide applicators questionnaire content validation: a Fuzzy Delphi Method”, Medical Journal of Malaysia, Vol. 72 No. 4, pp. 228-235.

Martín-de Castro, G., Delgado-Verde, M., Navas-López, J.E. and Cruz-González, J. (2013), "The moderating role of innovation culture in the relationship between knowledge assets and product innovation”, Technological Forecasting and Social Change, Vol. 80 No. 2, pp. 351-363, doi: 10.1016/j.techfore.2012.08.012.

Najafi-Tavani, S., Najafi-Tavani, Z., Naudé, P., Oghazi, P. and Zeynaloo, E. (2018), "How collaborative innovation networks affect new product performance: product innovation capability, process innovation capability, and absorptive capacity", Industrial Marketing Management, Vol. 73 May 2016, pp. 193-205, doi: 10.1016/j.indmarman.2018.02.009.

Nambisan, S. (2013), "Lage drachtigheidspercentages en kleine nesten na kunstmatige inseminatie", Tijdschrift Voor Diergeneeskunde, Vol. 125 No. 18, p. 553.

Newman, A., Tse, H.H.M., Schwarz, G. and Nielsen, I. (2018), "The effects of employees' creative selfefficacy on innovative behavior: the role of entrepreneurial leadership", Journal of Business Research, Vol. 89 September 2016, pp. 1-9, doi: 10.1016/j.jbusres.2018.04.001.

Nisula, A.M. and Kianto, A. (2013), "Evaluating and developing innovation capabilities with a structured method", Interdisciplinary Journal of Information, Knowledge, and Management, Vol. 8, pp. 59-82, doi: 10.28945/1902. 
Oke, A. (2013), "Linking manufacturing flexibility to innovation performance in manufacturing plants", International Journal of Production Economics, Vol. 143 No. 2, pp. 242-247, doi: 10.1016/ j.ijpe.2011.09.014.

Phan, K. (2013), "Innovation measurement: a decision framework to determine innovativeness of a company", Dissertations and Theses Paper 1017, doi: 10.15760/etd.1017.

Prajogo, D.I. (2016), "The strategic fit between innovation strategies and business environment in delivering business performance", International Journal of Production Economics, Vol. 171, pp. 241-249, doi: 10.1016/j.jpe.2015.07.037.

Rabelo, R.J. and Bernus, P. (2015), "A holistic model of buliding innovation ecosystems", IFACPapersOnLine, Vol. 48 No. 3, pp. 2250-2257, doi: 10.1016/j.ifacol.2015.06.423.

Rajesh, R. (2017), "Technological capabilities and supply chain resilience of firms: a relational analysis using total interpretive structural modeling (TISM)", Technological Forecasting and Social Change, Vol. 118, pp. 161-169, doi: 10.1016/j.techfore.2017.02.017.

Radujković, M. and Sjekavica, M. (2017), "Project management success factors”, Procedia Engineering, Vol. 196 June, pp. 607-615, doi: 10.1016/j.proeng.2017.08.048.

Rangus, K. and Slavec, A. (2017), "The interplay of decentralization, employee involvement and absorptive capacity on firms' innovation and business performance", Technological Forecasting and Social Change, Vol. 120, pp. 195-203, doi: 10.1016/j.techfore.2016.12.017.

Rasiah, R., Shahrivar, R.B. and Yap, X.S. (2016), "Institutional support, innovation capabilities and exports: evidence from the semiconductor industry in Taiwan", Technological Forecasting and Social Change, Vol. 109, pp. 69-75, doi: 10.1016/j.techfore.2016.05.015.

Ravichandran, T. (2018), "Exploring the relationships between IT competence, innovation capacity and organizational agility", Journal of Strategic Information Systems, Vol. 27 No. 1, pp. 22-42, doi: 10.1016/j.jsis.2017.07.002.

Reid, M., Hultink, E.J., Marion, T. and Barczak, G. (2016), "The impact of the frequency of usage of IT artifacts on predevelopment performance in the NPD process", Information and Management, Vol. 53 No. 4, pp. 422-434, doi: 10.1016/j.im.2015.10.008.

Richtnér, A., Brattström, A., Frishammar, J., Björk, J. and Magnusson, M. (2017), “Creating better innovation measurement practices", MIT Sloan Management Review, Vol. 59 No. 1, pp. $44-53$.

Saaty, T.L. (2006), "The analytic network process", in Decision Making with the Analytic Network Process, pp. 1-26, doi: 10.1007/0-387-33987-6.

Sahay, B.S. (2004), "Multi-factor productivity measurement model for service organisation", International Journal of Productivity and Performance Management, Vol. 54 No. 1, pp. 7-22, doi: 10.1108/17410400510571419.

Santoro, G., Vrontis, D., Thrassou, A. and Dezi, L. (2018), “The Internet of Things: building a knowledge management system for open innovation and knowledge management capacity", Technological Forecasting and Social Change, Vol. 136, pp. 347-354, doi: 10.1016/j.techfore.2017.02.034.

Saunila, M. and Ukko, J. (2012), "A conceptual framework for the measurement of innovation capability and its effects”, Baltic Journal of Management, Vol. 7 No. 4, pp. 355-375, doi: 10.1108/ 17465261211272139 .

Schroeder, R.G., Scudder, G.D. and Elm, D.R. (1989), "Innovation in manufacturing", Journal of Operations Management, Vol. 8 No. 1, pp. 1-15, doi: 10.1016/S0272-6963(89)80002-6.

Shahzad, F., Xiu, G.Y. and Shahbaz, M. (2017), "Organizational culture and innovation performance in Pakistan's software industry”, Technology in Society, Vol. 51, pp. 66-73, doi: 10.1016/j.techsoc. 2017.08.002.

Sirait, J. (2016), "The effect of interpersonal communication, school organizational culture, job satisfaction and work motivation to organizational commitment of the state primary school principals in North Tapanuli district", International Journal of Sciences: Basic and Applied Research (IJSBAR), Vol. 25 No. 1, pp. 363-388. 
Sözbilir, F. (2018), "The interaction between social capital, creativity and efficiency in organizations", Thinking Skills and Creativity, Vol. 27 December 2017, pp. 92-100, doi: 10.1016/j.tsc.2017.12.006.

Stålberg, L. (2018), “Adapting to dynamic conditions through continuous innovation in manufacturing”, Dissertations and Theses, ISBN: 978-91-7485-385-8; ISSN: 1651-4238.

Steiber, A. (2014), The Google Model: Managing Continuous Innovation in a Rapidly Changing World, Springer. doi: 10.1021/cen-v085n045.p003.

Steiber, A. and Alänge, S. (2013), "A corporate system for continuous innovation: the case of Google”, European Journal of Innovation Management, Vol. 16 No. 2, pp. 243-264, doi: 10.1108/ 14601061311324566.

Sun, H., Wong, S.Y., Zhao, Y. and Yam, R. (2012), “A systematic model for assessing innovation competence of Hong Kong/China manufacturing companies: a case study”, Journal of Engineering and Technology Management - JET-M, Vol. 29 No. 4, pp. 546-565, doi: 10.1016/j.jengtecman.2012.03.005.

Teece, D. and Pisano, G. (1994), “The dynamic capabilities of firms: an introduction”, Industrial and Corporate Change, Vol. 3 No. 3, pp. 537-556, doi: 10.1093/icc/3.3.537-a.

Tranfield, D., Denyer, D. and Smart, P. (2003), "Towards a methodology for developing evidenceinformed management knowledge by means of systematic review", British Journal of Management, Vol. 14 No. 3, pp. 207-222, doi: 10.1111/1467-8551.00375.

Ukko, J., Saunila, M., Parjanen, S., Rantala, T., Salminen, J., Pekkola, S. and Mäkimattila, M. (2016), "Effectiveness of innovation capability development methods", Innovation: Management, Policy and Practice, Vol. 18 No. 4, pp. 513-35, doi: 10.1080/14479338.2016.1233824.

Valmohammadi, C. and Dashti, S. (2016), "Using interpretive structural modeling and fuzzy analytical process to identify and prioritize the interactive barriers of e-commerce implementation", Information and Management, Vol. 53 No. 2, pp. 157-168, doi: 10.1016/j.im.2015.09.006.

Wu, H., Chen, J. and Jiao, H. (2016), "Dynamic capabilities as a mediator linking international diversification and innovation performance of firms in an emerging economy", Journal of Business Research, Vol. 69 No. 8, pp. 2678-2686, doi: 10.1016/j.jbusres.2015.11.003.

Xie, X.M., Zeng, S.X. and Tam, C.M. (2011), Towards Continuous Innovation for., Vol. 13 No. 3, pp. 361-375.

Yamin, S., Gunasekaran, A. and Mavondo, F.T. (1999), "Innovation index and its implications on organizational performance: a study of Australian manufacturing companies", International Journal of Technology Management, Vol. 17 No. 5, pp. 495-503, doi: 10.1504/IJTM.1999.002733.

Zhang, X. and Bartol, K. (2010), "Linking empowering ledership and employee creativity", Academy of Management Joumal, Vol. 53 No. 1, pp. 107-128, available at: https://s3.amazonaws.com/academia. edu.documents/31079623/Presentation_4_Empowerment.pdf?response-content-disposition=inline $\%$ 253Bfilename \%253DLinking_empowering_leadership_and_employ.pdf\&X-Amz-Algorithm =AWS4-HMAC-SHA256\&X-Amz-Credential=AKIAIWOWYYGZ2Y53UL.

Zhang, G. and Tang, C. (2017), "How could firm's internal R\&D collaboration bring more innovation?", Technological Forecasting and Social Change, Vol. 125 March, pp. 299-308, doi: 10.1016/j. techfore.2017.07.007.

Zheng, Y., Liu, J. and George, G. (2010), "The dynamic impact of innovative capability and inter-firm network on firm valuation: a longitudinal study of biotechnology start-ups”, Journal of Business Venturing, Vol. 25 No. 6, pp. 593-609, doi: 10.1016/j.jbusvent.2009.02.001.

Zhou, J., Bi, G., Liu, H., Fang, Y. and Hua, Z. (2018), "Understanding employee competence, operational IS alignment, and organizational agility - an ambidexterity perspective", Information and Management, Vol. 55 No. 6, pp. 695-708, doi: 10.1016/j.im.2018.02.002.

\section{Further reading}

Benitez, J., Castillo, A., Llorens, J. and Braojos, J. (2017), "IT-enabled knowledge ambidexterity and innovation performance in small U.S. firms: the moderator role of social media capability", Information and Management, Vol. 55 No. 1, pp. 131-143, doi: 10.1016/j.im.2017.09.004.
Holistic model for measuring CIC

-


Guan, J. and Ma, N. (2003), "Innovative capability and export performance of Chinese firms", Technovation, Vol. 23 No. 9, pp. 737-747, doi: 10.1016/S0166-4972(02)00013-5.

Hultink, E.J., Hart, S., Robben, H.S.J. and Griffin, A. (2000), "Launch decisions and new product success: an empirical comparison of consumer and industrial products", Journal of Product Innovation Management, Vol. 17 No. 1, pp. 5-23, doi: 10.1111/1540-5885.1710005.

Lianto, B., Dachyar, M. and Soemardi, T.P. (2020), "Modelling the continuous innovation capability enablers in Indonesia's manufacturing industry", Journal of Modelling in Management, Emerald Publishing, Vol. 15, pp. 1-34, doi: 10.1108/JM2-04-2020-0103.

Mir, M., Casadesús, M. and Petnji, L.H. (2016), "The impact of standardized innovation management systems on innovation capability and business performance: an empirical study", Journal of Engineering and Technology Management - JET-M, Vol. 41, pp. 26-44, doi: 10.1016/j.jengtecman. 2016.06.002.

Mohan, S.R. (2016), "Strategy and design of innovation policy road mapping for a waste biorefinery", Bioresource Technology, Vol. 215, pp. 76-83, doi: 10.1016/j.biortech.2016.03.090.

Morris, L. (2008), "Innovation metrics: the innovation process and how to measure it", November, available at: https://www.innovationlabs.com/publications/innovation-metrics/.

Muller, A., Välikangas, L. and Merlyn, P. (2005), "Metrics for innovation: guidelines for developing a customized suite of innovation metrics", Strategy and Leadership, Vol. 33 No. 1, pp. 37-45, doi: 10.1108/10878570510572590.

Stoker, J.I., Looise, J.C., Fisscher, O.A.M. and De Jong, R.D. (2001), "Leadership and innovation: relations between leadership, individual characteristics and the functioning of R\&D teams", International Journal of Human Resource Management, Vol. 12 No. 7, pp. 1141-1151, doi: 10. 1080/09585190110068359.

Xie, Y., Xue, W., Li, L., Wang, A., Chen, Y., Zheng, Q., Wang, Y. and Li, X. (2018), "Leadership style and innovation atmosphere in enterprises: an empirical study", Technological Forecasting and Social Change, Vol. 135 June, pp. 257-265, doi: 10.1016/j.techfore.2018.05.017.

\section{About the authors}

Benny Lianto is an Assistant Professor at the Department of Industrial Engineering, University of Surabaya, Indonesia. He holds a B.Eng. Degree in Industrial Engineering from the University of Surabaya in 1992. He received a master's degree in Industrial engineering and management from Bandung Institute of Technology, Indonesia. He is now pursuing her doctoral degree at Universitas Indonesia (UI). His areas of interest are in the innovation strategy and technopreneurship. His main research area is on developing an organization to become an innovative organization in the digital era. Benny Lianto is the corresponding author and can be contacted at: b_lianto@staff.ubaya.ac.id

Muhammad Dachyar, $\mathrm{PhD}$ is a Professor at the Industrial Engineering Department, Universitas Indonesia (UI), Indonesia. He received $\mathrm{PhD}$ from Dept. of Industrial Engineering, Bogor Agricultural Institute, Indonesia. He received a master's degree from VUB Brussel, Belgium majoring in industrial location and development. His areas of interest are in management information system, service management, business process reengineering, project management and maintenance management information system. His research activities are carried out through an academic and consulting project.

Tresna Priyana Soemardi $\mathrm{PhD}$ is a Professor at the Mechanical Engineering Department, Universitas Indonesia (UI), Indonesia. He received $\mathrm{PhD}$ from Ecole Centrale de Paris-France majoring in applied mechanics and advanced composites materials. His areas of interest are in Applied mechanics and composite material, product design and development, product innovation and innovation strategy management. His research activities are carried out through an academic and consulting project. He also as Supervisor and Co-Supervisor for Magister and Doctorat Dissertation on Innovation and Strategic Management at Faculty of Business and Economics, Universitas Indonesia, Indonesia.

For instructions on how to order reprints of this article, please visit our website:

www.emeraldgrouppublishing.com/licensing/reprints.htm

Or contact us for further details: permissions@emeraldinsight.com 


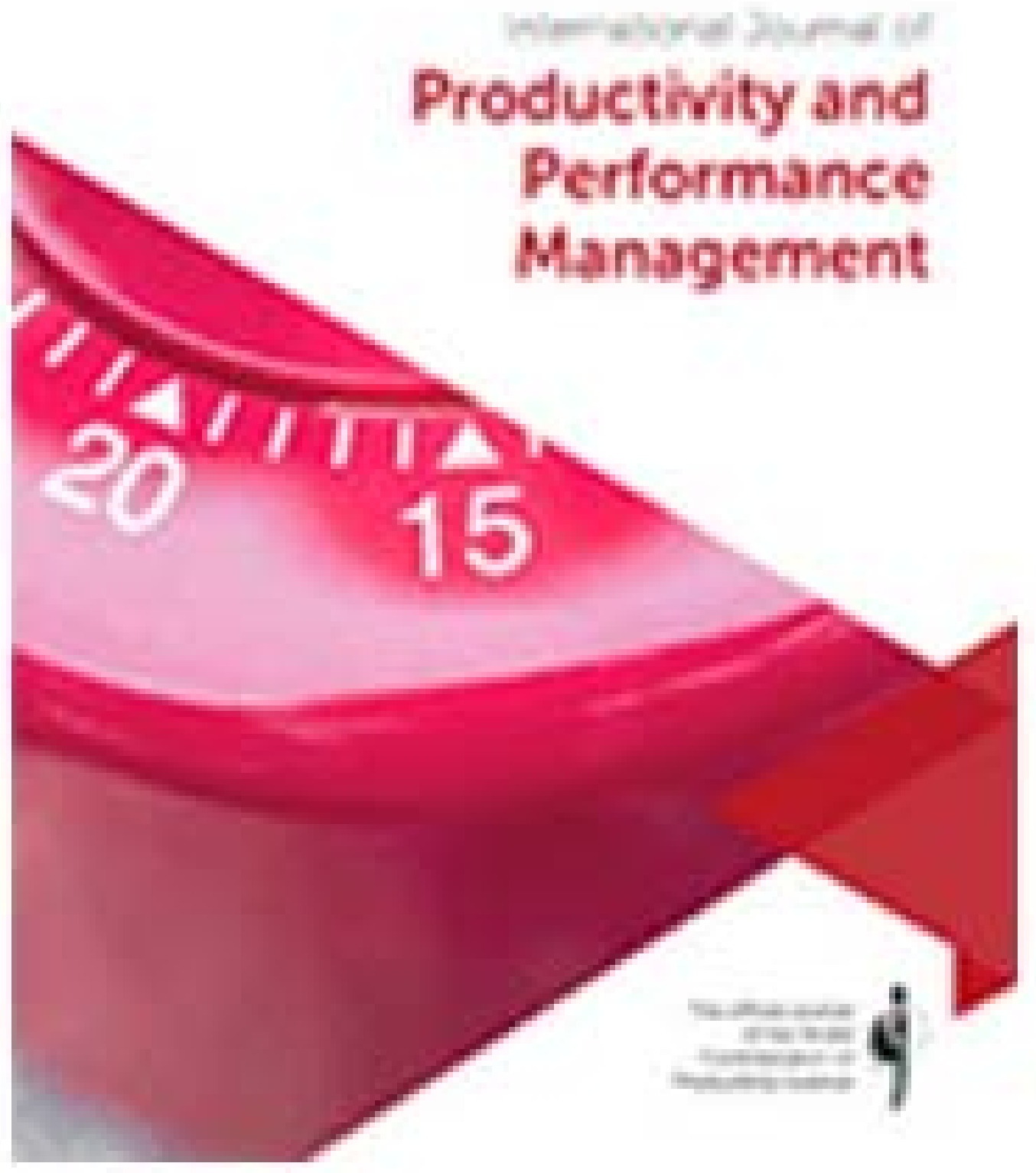




\section{International Journal of Productivity and Performance Management}

COUNTRY

United Kingdom

Universities and research Institutions in United Kingdom

Journals
COVERAGE

INFORMATION

Homepage

How to publish in this journa

Iuisa huatuco@york.ac.uk

2004-2020
Smart Lab Inventory Manag $\epsilon$

Adopt Digital Transformation

LANEXO" System helps to save time spent

epetitive, error-prone operational tasks.

anexosystem.com

\section{SUBJECT AREA AND CATEGORY}

Business, Management and Accounting Business, Management and Accounting (miscellaneous)

Strategy and Management

\section{PUBLISHER}

Emerald Group Publishing Lto

ISSN

17410401

\section{1}

SCOPE

The International Journal of Productivity and Performance Management publishes double-blind peer-reviewed papers. The main types include original research and reflective practice papers, though other forms are considered. Each issue includes high-quality content covering all aspects of productivity and performance management from a wide range of international contexts, sectors and applications. The journal's distinctiveness flows from: (a) its substantial longevity in the field of productivity and performance management continuing from the previous titles: Time and Motion Study then Work Study. (b) its growth from its roots in industrial engineering and operations management to encompass many other perspectives and (c) its commitment to the practitioner voice, encouraged through reflective practice articles. The journal's scope draws from the fields of Operations \& Supply Chain Management, Industrial Engineering, Marketing. Economics, Accounting. Human Resource Management and Organizational Behaviour. Coverage includes, but it is not limited to: Performance management Performance measurement tools \& techniques Productivity measurement \& development Organizational design \& methods Process analysis, engineering \& re-engineering Quality \& business excellence management Lean approaches Project \& programme management. 
FIND SIMILAR JOURNALS ?

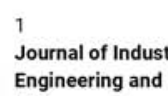

ESP
2

Benchmarking

GBR

$55 \%$

similarity

$53 \%$

similarity

International Journal of Supply Chain Management GBR

Reduce Lab Chemical Waste

Smart Lab Inventory Management

LANEXO- System helps to save time spent on repetitive, error-prone operational taska

Journal of Global Operations and Strategic Sourcing GBR

\section{$49 \%$}

similarity

Journal of Advances in Management Research GBR

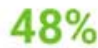

options :

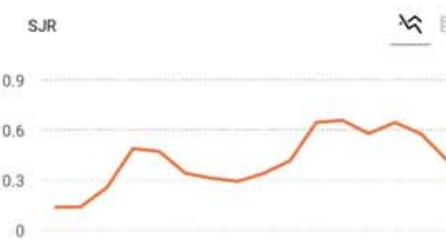

$\begin{array}{llllllll}2005 & 2007 & 2009 & 2011 & 2013 & 2015 & 2017 & 2019\end{array}$

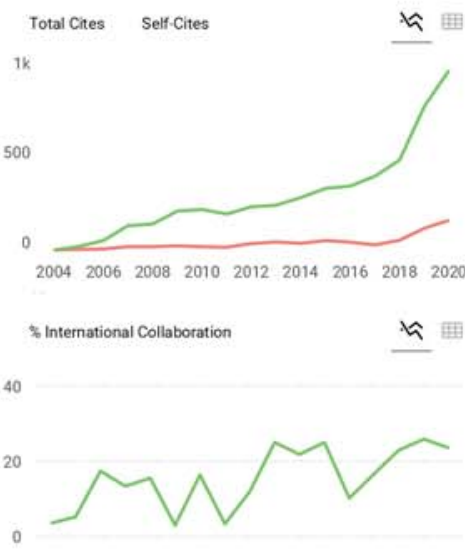

$\begin{array}{lllllllll}2004 & 2006 & 2008 & 2010 & 2012 & 2014 & 2016 & 2018 & 2020\end{array}$

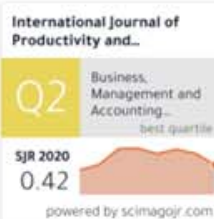

- Show this widget in your own website

Just copy the code below and paste within your $\mathrm{html}$ code:

<a href="https://www.scin

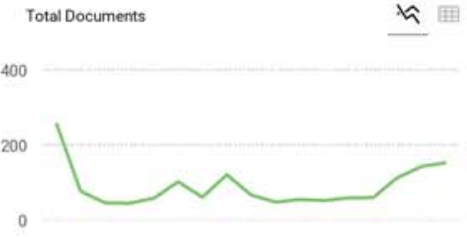

$2004 \quad 2006 \quad 2008 \quad 2010 \quad 2012 \quad 2014 \quad 2016 \quad 2018 \quad 2020$

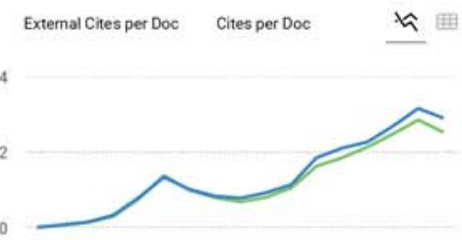

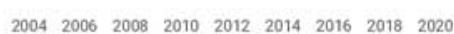
Citable documents Noncitable documents th

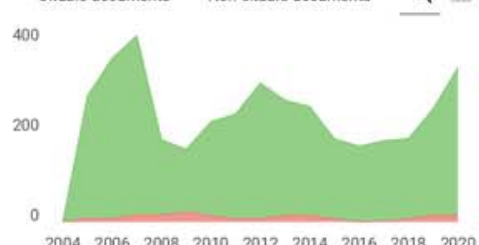
$\begin{array}{lllllllll}2004 & 2006 & 2008 & 2010 & 2012 & 2014 & 2016 & 2018 & 2020\end{array}$

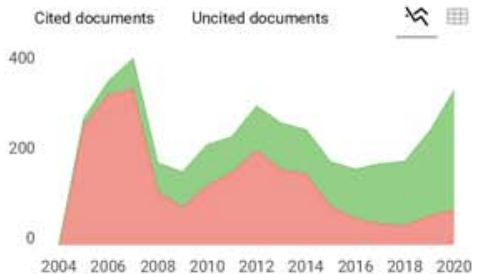

G sclmago Graphica

Explore, visually communicate and make sense of data with our new free tool.

Get it

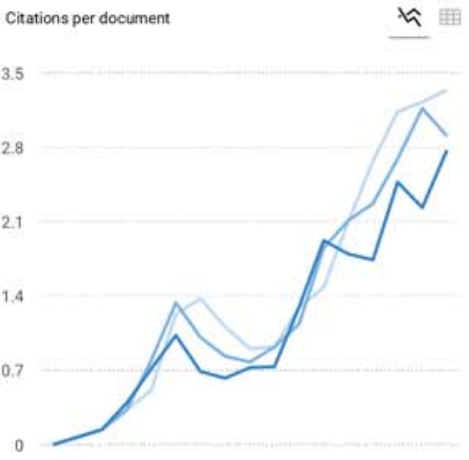

$20042006 \quad 2008 \quad 2010 \quad 2012 \quad 2014 \quad 2016 \quad 2018 \quad 2020$ Cites / Doc. (4 years) Cites / Doc. (3 years) 
Metrics based on Scopus $\circledast$ data as of April 2021

Leave a comment

Name

Email

(will not be published)

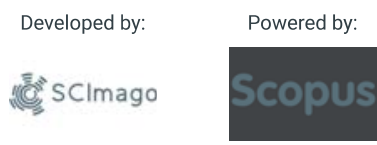

Follow us on @ScimagoJR

Scimago Lab, Copyright 2007-2020. Data Source: Scopus ${ }^{\circledR}$ 


\section{Source details}

\section{International Journal of Productivity and Performance Management}

Scopus coverage years: from 2004 to Present

Publisher: Emerald

ISSN: 1741-0401

Subject area: Business, Management and Accounting: General Business, Management and Accounting

Business, Management and Accounting: Strategy and Management

Source type: Journal
View all documents >
Set document alert
$\square$ Save to source list Source Homepage

CiteScore 2020

\section{CiteScore CiteScore rank \& trend Scopus content coverage}

i Improved CiteScore methodology

CiteScore 2020 counts the citations received in 2017-2020 to articles, reviews, conference papers, book chapters and data papers published in 2017-2020, and divides this by the number of publications published in 2017-2020. Learn more >

CiteScore 2020

$3.5=\frac{1,292 \text { Citations } 2017-2020}{373 \text { Documents } 2017-2020}$

Calculated on 05 May, 2021
CiteScoreTracker 2021 (i)

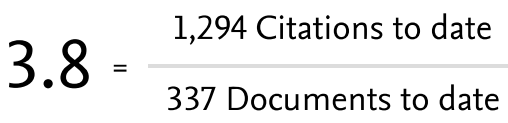

Last updated on 04 September, 2021 • Updated monthly

\section{CiteScore rank 2020}
Category
Rank Percentile

Business, Management

and Accounting

\#50/218

77th

- General Business,

Management and

Accounting

Business, Management

and Accounting

\#135/440

69th$$
\text { Strategy and }
$$

View CiteScore methodology $>$ CiteScore FAQ $>$ Add CiteScore to your site $\mathbb{C}$ 

About Scopus
Русский язык
Privacy matters
ELSEVIER Terms and conditions $\pi \quad$ Privacy policy $\pi$
Copyright (C) Elsevier B.V ז. All rights reserved. Scopus ${ }^{\circledR}$ is a registered trademark of Elsevier B.V.
We use cookies to help provide and enhance our service and tailor content. By continuing, you agree to the use
of cookies. 


\section{Editorial team}

\section{Co-Editor}

Dr Luisa Huaccho Huatuco

University of York - UK

luisa.huatuco@york.ac.uk

Dr Nicky Shaw

Leeds University Business School - UK

N.E.Shaw@lubs.leeds.ac.uk

\section{Editorial Assistant}

Jennifer Webster

University of Leeds - UK

jeniwebster123@gmail.com

\section{Regional Editor}

Dr Cláudia S Sarrico (Europe)

Technical University of Lisbon - Portuga!

\section{Associate Editor}

Dr. Berk Kucukaltan

School of Applied Sciences, Trakya University - Turkey

berkkucukaltanatrakya.edu.tr

Professor Sai Sudhakar Nudurupati

Gandhi Institute of Technology and Management University - india

snudurup@agitam.edu

Professor Arash Shahin

University of isfahan - Iran

shahinease.ui.ac.ir

Dr. Jitesh J. Thakkar

National Rail and Transportation institute (NRT) - india

jitesh.thakkar@anrti.edu.in

Dr Lihong Zhang

University of Manchester - UK

Lihong.Zhangamanchester.ac.uk 


\title{
Publisher
}

Daniel Ridge

Emerald Group Publishing - USA

dridge@emeraldgroup.com

Journal Editorial Office (For queries related to pre-acceptance)

\author{
Sharon Sebastian Kanappally \\ Emerald Publishing \\ sharon.emerald@kwglobal.com
}

Supplier Project Manager (For queries related to post-acceptance)

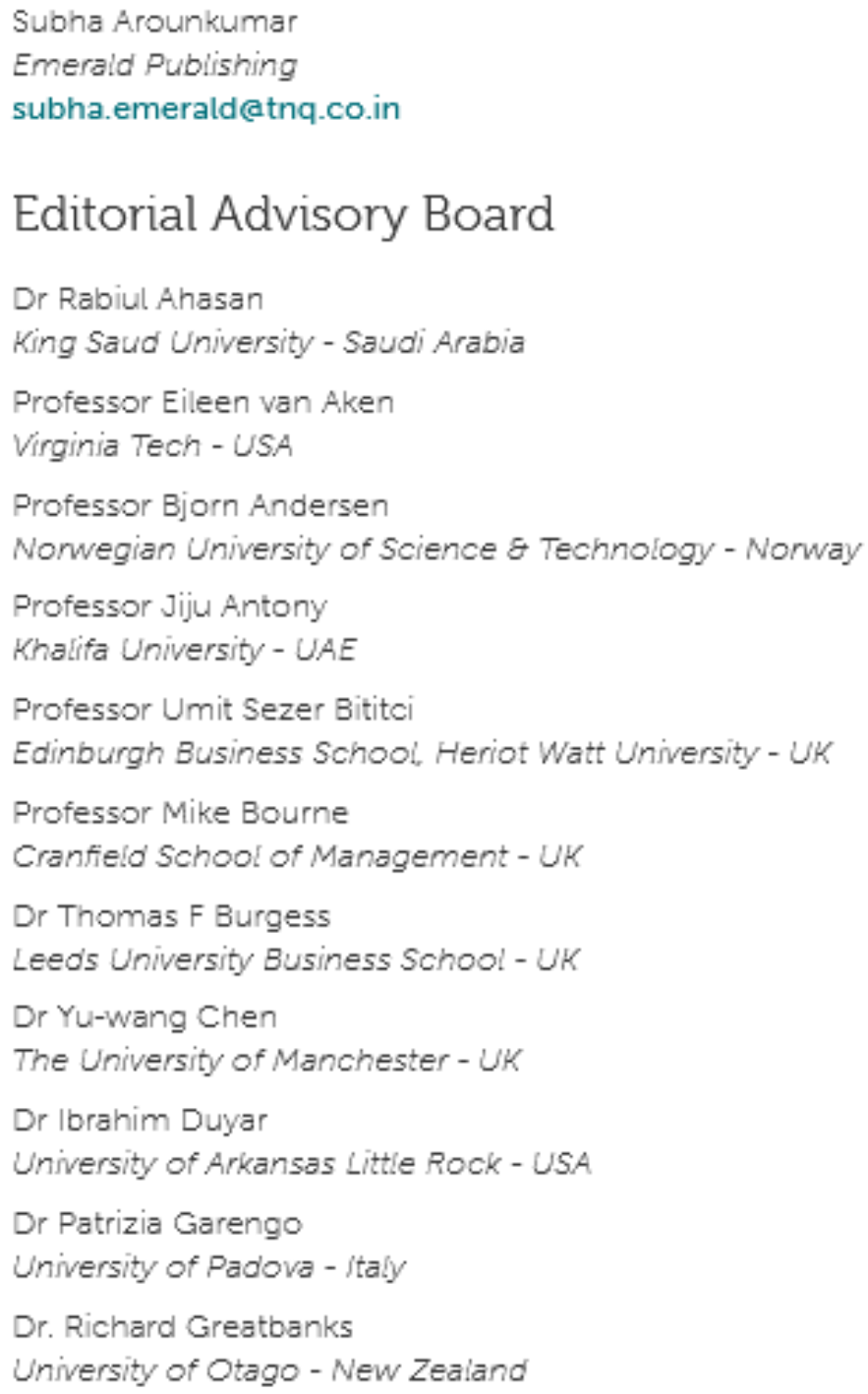


Professor Claire Hannibal

Liverpool John Moores University - UK

Professor Rajashekharaiah Jagadeesh

SDM institute for Management Development - India

Professor Wagner Cezar Lucato

Nove de Juho University - Brazil

Professor Jill MacBryde

University of Strathclyde - UK

Dr Jane Maley

Charles Sturt University - Australia

Dr Kepa Mendibil

University of Strathclyde - UK

Dr Jihad Mohammad

Qatar University, Doha - Qatar

Dr Matteo Mura

University of Bologna - Italy

Professor Sai Nudurupati

Gandhi Institute of Technology and Management - India

Professor Low Sui Pheng

Nationa! University of Singapore - Singapore

Professor Zoe Radnor

University of Law - UK

Professor Nick Rich

Swansea University - UK

Dr Sanjay Kumar Singh

School of Business, Maynooth University, Maynooth - Ireland

Dr. Narayanasamy Sivasankaran

XLRI Xavier School of Management - India

Dr Alison Smart

University of Glasgow - UK

Professor Amrik Sohal

Monash University - Australia

Dr Mike Tse

Cardiff University - UK

Dr Morteza Yazdani

ES/C Business \& Marketing School - Spain

Professor Li Zheng

Tsinghua University - People's Republic of China

Dr Andre A de Waal

Wittenborg University of Applied Sciences - The Netherlands 


\section{International Journal of Productivity and Performance Management}

Issue(s) available: 141 - From Volume: 53 Issue: 1, to Volume: 70 Issue: 6

Subject: Strategy > Organizational performance

Subscribe to table of contents alerts $\mathrm{x}$ i $\mathrm{RSS}$ feed

Search within this journal

$Q$

\section{All issues EarlyCite}

Modelling supply chain risks and their impacts on the performance of the sago starch agro-industry

Syamsul Anwar, Taufik Djatna, Sukardi, Prayoga Suryadarma

i. $\operatorname{PDF}(2.7 \mathrm{Mg})$

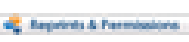

Supply chain risks (SCRS) have uncertainty and interdependency characteristics that must be incorporated into the risk assessment stage of the SCR management framework...

The impact of contingency fit on organisational performanoe: an empirical study

Abdallah Amhalhal, John Anchor, Nicoleta S. Tipi, Sara Elgazzar

1. PDF (2:32 KE)

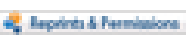

The research investigates the eflectiveness of the performance measurement alignment approach which claims that measurement diversity (multiple performance measures...

Measure human capital because people really matter: development and validation of human capital scale (HuCapS)

Rinki Dahiya, juhi Raghuvanshi

Notwithstanding the findings of several published articles on human capital, there is scarcity of a comprehensive instrument to measure it. In this direction, the-

Assessing audit outcomes of pre-determined objectives in a public institution (South Africa)

Stella Banyana Mosimege, Tyanai Masiya results to improve public service delivery. The practice of development of performance.. 
Impact of sustainable supply chain management and customer relationship management on organizational performance

Saikat Das. H.M. Kamrul Hassan

This paper aims to assess the effect of sustainable supply chain management (SSCM).

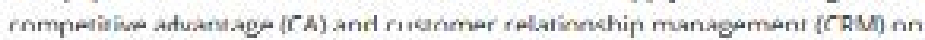

A holistic model for measuring continuous innovation capability of manufacturing industry: a case study

Benny Lianto Muhammad Dachyar, Tresna Prìana Soemardi

The purpose of this paper is to develop a comorehensive continuous innovation

capability (ClO measurement model in manufacturing sectors.
PDF CI ME

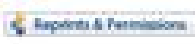

Does managerial capability always drive performance? Empirical examinations of small and medium firms (SMEs) in a developing economy

Ahmed Agyapong, Suzzie Owiredua Ajobo, Samuel Yaw Akomea

The paper sought to uncover the condinions under which managerial capability enhances performance while considering the role of social capital within the unique boundary...

Technological innovation management: understanding difficulties in an emenging counhy tu enhanos madnufaclenens pen furmanve

Lucas M. Mavos, Izabela Simon Rampasso, Osvaldo LG. Quelinas, Walter Leal Filho

Rosley Anholon

This study aims to discuss the difficulties faced by two large Brazilian industrial

companies ir technological innovation management

Effects on ccrporate performance through ISS-enabled strategy-making on dynamic and improvisational capabilities

This study develops the idea that resource orchestration (RO) of ISS- enabled strategy' making (ISS.SM) can influence dynamic and improvisational capabilities in innovation.. 